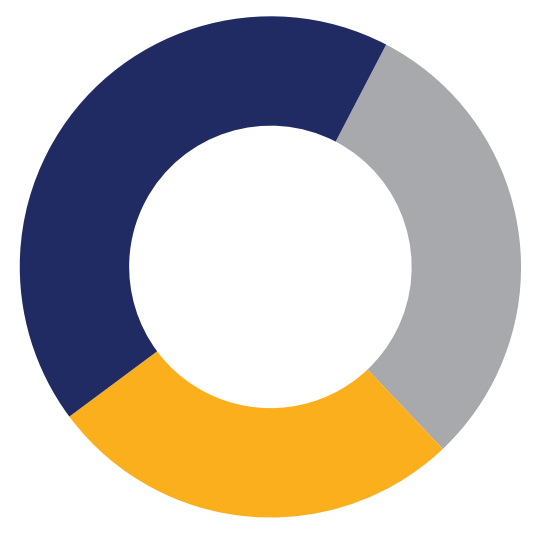

RAPID EVIDENCE REVIEW

\title{
Effective Treatment and Support for Problem Gambling
}

Prepared for: Gambling Commission

MARCH 2020 


\section{Team}

Lindsay Kalbfleisch (Lead)

David Baxter

Sheila McKnight

Travis Sztainert

Maha Sohail

\section{Reviewed by}

Trudy Smit Quosai

\section{Design and Layout by}

Ebb + Flow Creative

\section{SUGGESTED CITATION:}

Gambling Research Exchange Ontario (GREO). (2020). Effective Treatment and Support for Problem Gambling. Report prepared for the Gambling Commission, Birmingham, UK. https://doi.org/10.33684/2020.005

\section{About Us}

GREO is an independent knowledge translation and exchange organization with almost two decades of international experience in generating, synthesising, and mobilising research into action across the health and wellbeing sectors.

GREO helps organisations improve their strategies, policies, and practices by harnessing the power of evidence and stakeholder insight. Services we offer include sourcing and synthesising evidence, creating knowledge and education products, facilitation and stakeholder engagement, data and knowledge management support, evaluation, and applied research.

\section{Contact Information}

Email: info@greo.ca

Phone: 519-763-8049 


\section{| Table of Contents}

Executive Summary

\begin{tabular}{llr}
\hline Section 1 & Introduction & 7 \\
Section 2 & Methods & 8 \\
Section 3 & Cognitive Behavioural Therapy & 11 \\
Section 4 & Motivational Interventions & 19 \\
Section 5 & Remote and Self-Help Interventions & 24 \\
Section 6 & Helplines & 29 \\
Section 7 & Treatment Involving Concerned & 32 \\
& Significant Others & \\
Section 8 & Residential Treatment & 35 \\
Section 9 & Pharmacological Treatments & 39 \\
Section 10 & Brain Stimulation & 43 \\
Section 11 & Gamblers Anonymous & 46 \\
Section 12 & Emerging Treatment Modalities & 48 \\
Section 13 & Discussion and Conclusions & 51
\end{tabular}

Appendix A Glossary of Key Terms 55

Appendix B Search Strings 63

Appendix C Summary of Study Details 65 


\section{Executive Summary}

The National Strategy to Reduce Gambling Harms has identified the need to make significant progress towards truly national treatment and support options as one of its priority actions. This priority area is shared by GambleAware, another key stakeholder in the Great Britain's (GB) gambling treatment and support landscape. The evidence upon which GB's current gambling treatment strategy is based is outdated, and GambleAware has begun the planning process towards an update to the current treatment strategy.

A rapid evidence review was commissioned to provide an updated evidence base on treatment and support for problem gambling in order to inform future growth, improvement, and evaluation of problem gambling treatment services across GB. The report covers ten key treatment topics including:

, Cognitive Behavioural Therapy

, Motivational Interventions

, Remote and Self-Help Interventions

> Helplines

> Treatment Involving Concerned Significant Others

> Residential Treatment

, Pharmacological Treatments

> Brain Stimulation

> Gamblers Anonymous

, Emerging Treatment Modalities

\section{Cognitive Behavioural Therapy}

Evidence suggests that cognitive behavioural therapy (CBT) is the most effective modality for treating problem gambling. CBT is shown to have robust, positive, short and long-term effects on problem gambling, across gambling types and severity 
levels. CBT may be most effective when delivered in-person, in an out-patient setting, using a combination of exposure therapy and cognitive restructuring techniques.

While some evidence suggests six-to-eight sessions of CBT (or chapters if self-directed) may be most effective, other research supports the use of brief interventions. Research suggests that CBT may be quite effective for supporting key populations of interest (e.g., women, and Black, Asian, and minority ethnicities [BAME] communities), but more research is needed to fully understand treatment outcomes among these somewhat understudied populations. As well, internet or computerised CBT (iCBT) demonstrates promising outcomes in terms of reducing gambling problems, and enhancing mental health and quality of life. iCBT may help to reduce treatment barriers among gamblers who do not wish to, or are unable to seek face-to-face treatment, though research recommends some degree of therapist support for gamblers engaging in online iCBT.

\section{Motivational Interventions}

The literature on motivational interventions for treatment of problem gambling is somewhat limited, and the results are not particularly robust or maintained consistently over time. There is some evidence to suggest that brief motivational interventions, and in-person and remote motivational interviewing and motivational enhancement therapy, can have a positive impact on problematic gambling behaviours. Motivational interventions may be particularly useful in terms of their pre-treatment application, as they are shown to enhance the likelihood of attending treatment and to decrease dropout. A growing body of literature specifically supports the combination of motivational interventions with CBT. Overall, more research is needed to understand the use of motivational interventions among diverse populations.

Limited research suggests motivational interventions may have a strong cross-cultural application effective for treating gambling problems within BAME communities.

\section{Remote and Self-help Interventions}

Remote and self-help interventions appear to reduce problem gambling and related harm, particularly among women who may feel more comfortable in online, singlegender treatment and support spaces. The most commonly used online therapeutic 
modalities are CBT and motivational interventions, but research suggests that a blend of modalities may be appropriate for internet-based interventions.

Offline, research supports the use of workbook-based treatment for addressing problem gambling symptoms and related harms. Though approaches to remote interventions vary considerably, commonalities between effective interventions included in this report appear to be self-direction, cognitive behavioural and motivational techniques, goal setting, some degree of relationship/interaction with a clinician, and access to information about normative behaviours for purposes of self-comparison. Both online and offline remote interventions can be particularly useful for women and other groups who may face barriers, or who may be less likely to access face-to-face treatment.

\section{Helplines}

The research on gambling helplines as a form of treatment and as a pathway to treatment is somewhat lacking and inconclusive. Evidence sourced suggests that helplines may be a good resource for supporting women, who may otherwise be less likely to engage with problem gambling supports. One study found that offering a brief intervention via a gambling helpline may help to reduce problem gambling and related mental health symptoms, though this idea was not supported by the findings of a review on the topic. Research suggests that helplines may be an important pathway to further treatment, and that staff can help to increase a caller's likelihood of seeking treatment by understanding and encouraging motivations for treatment-seeking, and booking a caller's initial appointment with a treatment provider during the call.

\section{Treatment Involving Concerned Significant (Affected) Others}

Problematic gambling does not only harm the individual gambler, but also concerned significant others (CSOs) in their lives. Available research, while limited, shows that involving CSOs in problem gambling treatment can benefit both the CSO and the person who gambles. Problem gamblers who have a concerned significant other, such as a spouse, sibling, parent, or loved one as part of their treatment sessions may 
have better treatment outcomes. Engaging a spouse in treatment (rather than a parent, sibling, or other (SO) may be particularly impactful. As well, pilot research suggests that harms experienced by CSOs can be addressed through couple-specific modalities, such as online behavioural couples therapy and/or congruence couples therapy, delivered online or in-person.

\section{Residential Treatment}

Residential treatment is generally accessed by a small sub-section of treatmentseeking problem gamblers. The research suggests that being immersed in a supportive environment, away from day-to-day challenges and stressors, can be particularly beneficial for some patients, particularly those with complex needs and comorbid conditions. Recent research on residential treatment for problem gambling is lacking, and more evidence is needed to understand which factors influence the efficacy of this form of treatment (e.g., length of stay, treatment modalities and allied services included, etc.). However, given the nature of patients who access residential care, research does recommend that residential treatment providers adopt evidencedbased practices and procedures for treating individuals with co-occurring disorders. As well, research identifies several patient characteristics that may predict treatment dropout (e.g., high debt, depression, experiences of childhood adversity; see Residential Treatment section for full list) and recommends that treatment providers develop and implement interventions to reduce dropout among key groups.

\section{Pharmacological Interventions}

Apart from extreme cases, pharmacological treatments are not currently used for treating gambling problems in Great Britain. Currently there is no drug approved for the treatment of problem gambling. While the evidence on pharmacological treatment remains somewhat inconclusive, some studies do demonstrate promising results. Recent literature tests the efficacy of dopamine antagonists, opioid antagonists, selective serotonin reuptake inhibitors (SSRIs), and glutamatergic agents for problem gambling treatment. Available evidence suggests that naltrexone (an opioid antagonist) may demonstrate the most potential. Overall, more longterm, placebo-controlled, double-blind studies are needed to determine which pharmacological treatment protocols are effective for addressing gambling problems. 


\section{Brain Stimulation}

Outside of extreme cases, brain stimulation is not currently used for treating gambling problems in Great Britain. Research on the use of brain stimulation for treating gambling problems is somewhat inconclusive and subject to several limitations, including small sample sizes, inconsistencies in study design and treatment protocols, and lack of information about the mechanisms of action and change. The literature sourced suggests that repetitive transcranial magnetic stimulation ( $r$-TMS) may help reduce cravings to gamble and enhance cognitive function among gamblers, and continuous theta burst stimulation (c-TBS) may reduce the physiological responses that can reinforce gambling behaviours (e.g., blood pressure). More long-term studies including large, demographically representative samples and consistent treatment protocols are needed to better understand the efficacy of brain stimulation for treating problem gambling.

\section{Gamblers Anonymous}

The body of recent literature on efficacy of Gamblers Anonymous (GA) is extremely limited and descriptive in nature. Available evidence suggests that GA is most accessed by men and may not be an appropriate option for the management of comorbid mental health challenges. The findings of two recent studies suggest that GA might be most effective when paired with another treatment modality (CBT or stress management). Overall, more robust research is needed to understand whether $\mathrm{GA}$, on its own, can lead to strong and positive outcomes for problem gamblers.

\section{Emerging Treatment Modalities}

Recent literature identifies several novel modalities that may help to treat gambling problems. Pilot studies suggest that, among gamblers, cognitive remediation may enhance mental skills and self-control, psychodynamic therapy may reduce problem gambling (PG), depression, and anxiety, and arts-based treatment may help support and connect women. Researchers and treatment providers may want to continue to explore the application of these modalities, particularly in terms of targeting underserviced populations (e.g., women and those with comorbid disorders). 
This report also provides discussion and contextualisation of the literature.

In summary:

> Cognitive behavioural therapies continue to be the most effective treatment for problem gambling but, as with many problem gambling treatment modalities, major barriers to effectiveness include low treatment uptake and high dropout rates.

, Given the challenges related to treatment uptake and dropout, the evidence also supports the use of modalities that increase treatment uptake, including motivational interventions, helplines, and remote and self-help interventions.

> Patients with more complex, co-occurring diagnoses may benefit from problem gambling treatment that specifically addresses sources of anxiety and depression, and/or residential treatment options. Offering treatment involving concerned significant others may help to mitigate the gambling harms experienced by affected others.

> Other treatment modalities demonstrate some promising results in a problem gambling context, but more robust long-term research is needed to truly understand their effectiveness and potential role within an overall treatment strategy.

> As literature was sourced internationally, context-specific evaluation will be an important step to understanding the effectiveness of these key treatment modalities within the Great Britain population. 


\section{Section 1 Introduction}

Progress toward a truly national gambling treatment and support strategy is a common priority among key stakeholders in Great Britain. This priority is reflected in the Gambling Commission's research programme, the National Strategy to Reduce Gambling Harm, and GambleAware's strategic plan. Currently, most gambling treatment in GB is commissioned through GambleAware and consists of psychosocial interventions, problem gambling helplines, psychiatric care, residential treatment, and counselling and cognitive behavioural therapy (CBT). GambleAware is in the process of reviewing problem gambling treatment in GB, toward a goal of updating the current treatment system.

To inform this strategic priority, the Gambling Commission has commissioned a rapid review of evidence on treatment and support for gambling problems. Although there is no agreed upon definition, rapid evidence reviews generally examine evidence related to a specific question, in a way that can be replicated (see Methods section for more detail). Rapid reviews are also usually completed within six months to meet deadlines, ${ }^{1}$ such as for policy decisions or practice changes.

This review summarises recent evidence on the overall effectiveness of several treatment modalities. Research demonstrates that treatment-related factors (e.g., treatment setting and degree of clinician involvement) influence treatment outcomes across modalities. Where available, this review will highlight the circumstances under which various treatment modalities are most effective. Additionally, research identifies that several patient-related factors (e.g., gender, ethnocultural background) influence the efficacy of treatment. Where available, this review also identifies which key populations may benefit from specific treatment modalities and how modalities can be structured to meet the needs of specific patient groups.

This review also aims to identify major gaps in the evidence and what considerations should be taken into account when evaluating and improving provision of treatment services. Given the nature of the research focus, this review primarily covers research related to treatment-seeking gamblers who meet clinical criteria for problem gambling, pathological gambling, or gambling disorder (assessment tools vary across studies), as opposed to those experiencing low or moderate harm from gambling. However, treatment modalities for those who are affected by someone's gambling are also included. 


\section{Section 2 Methods}

\section{SEARCH STRATEGY}

For this review, we followed the PRISMA reporting guidelines for systematic reviews, ${ }^{2}$ modified for a rapid review protocol as set out by Haby et al. ${ }^{1} \mathrm{~A}$ rapid evidence review was necessary to fit the timelines of anticipated policy decisions. To achieve a "rapid" timeline for an evidence review on a broad topic, we employed a relatively narrow time period, including single studies published since 2014. To supplement this recent evidence base, we also included topical systematic reviews and meta-analyses published since 2009. Systematic reviews and meta-analyses rigorously summarise existing evidence, including analysis of the scientific quality of individual studies. Thus, this represented an efficient way to include expert analysis of earlier research, while also summarising the latest available research.

The rapid timeline and broad topic required an iterative systematic search strategy aiming for more precise search results. We began with a narrow search focused on outcomes of problem gambling treatments and organised the results according to treatment modalities. If fewer than five articles were retrieved for any of the treatment modalities currently offered in Great Britain, we performed supplementary searches specifically on those treatments. The initial searches were performed on 16 October 2019, and supplementary searches were performed on 14 November 2019.

The first set of searches required search results to be indexed under a "Treatment outcomes" topic. We searched the medical literature database PubMed for studies focused on treatment outcomes for problem gambling treatment, and searched the GREO Evidence Centre for research snapshots and grey literature reports under the topic "Interventions".

The initial searches yielded enough results for all necessary topics, except for residential treatment programs and problem gambling helplines, which are currently offered in Great Britain. We performed supplementary searches on PubMed and PsycINFO for these topics, using the database's subject headings for those concepts (for example, helplines are referred to as "hotlines" in PubMed, and "hot line services" in PsyclNFO). Detailed information about all searches, including working search strings, is available in Appendix B. 


\section{INCLUSION AND EXCLUSION CRITERIA}

The inclusion and exclusion criteria for this review are detailed below. Of particular note is that no limits were set on the types of study designs for single studies to be included in the review. This is because the many different forms of treatment covered in this review will be at various stages, in terms of the number and types of studies available. Thus it was not feasible to set any restrictions on the types of studies included.

\section{Inclusion Criteria}

> Include articles about forms of treatment for problem gambling, as outlined in the "Treatment and Support" section of the Gambling Commission's National Strategy to Reduce Gambling Harms.

> Include articles that compare the relative effectiveness of multiple forms of treatment, or compare the relative effectiveness of one form of treatment for multiple demographic groups.

, Include experimental, observational, and qualitative studies published in 2014 or later.

, Include systematic review and meta-analysis articles published in 2009 or later.

\section{Exclusion Criteria}

> Exclude articles about gambling interventions falling under the topics "Prevention and Education" or "Industry-based Harm Minimisation", as defined in the Gambling Commission's National Strategy to Reduce Gambling Harms (e.g., self-exclusion).

, Exclude articles about gambling harm as an outcome of treatment of other conditions (e.g., problem gambling resulting from pharmacological treatment for Parkinson's disease).

, Exclude articles not written in English.

, Exclude articles with no electronic access.

\section{Search Results}

The results are detailed in the PRISMA diagram below. The first round of searches retrieved 259 results, and the second round focused on helplines and residential treatments retrieved 22 results. After removing duplicates, there were 160 unique articles and reports. All screening for inclusion/exclusion was done during the data extraction process. 67 articles were excluded at this stage for reasons outlined in the PRISMA diagram. As a result, 93 records were included in the evidence synthesis, representing ten treatment modalities. 
281 records identified through database searches

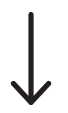

160 of records after duplicates removed

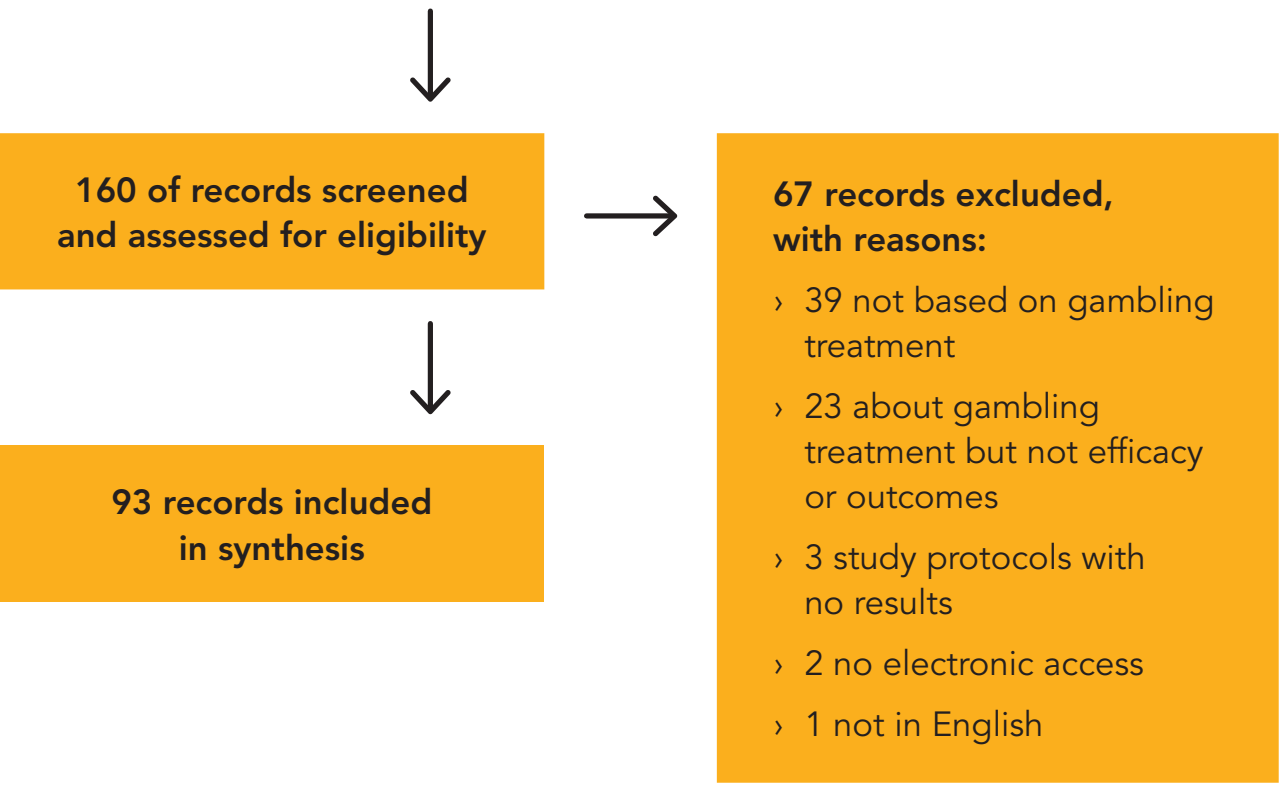




\section{Section 3 Cognitive Behavioural Therapy}

\section{INTRODUCTION}

This section provides an overview of the efficacy of cognitive behavioural therapy (CBT) for the treatment of problem gambling. CBT approaches aim to change the way patients think about gambling and reduce their gambling behaviours, ${ }^{3}$ and generally include exposure therapy (ET) and cognitive restructuring (CR). Based on the current search strategy, CBT is the problem gambling treatment modality with the greatest evidence base.

\section{OVERALL EFFICACY OF CBT FOR TREATING GAMBLING PROBLEMS}

Evidence suggests that cognitive behavioural therapies are the most effective type of treatment for gambling problems. ${ }^{4}$ Overall, research demonstrates that CBT can have robust short-term and long-term effects on problem gambling, and related harms (e.g., quality of life, emotional wellbeing) (5, $6^{6}$ across gambling types ${ }^{5}$ and severity levels. ${ }^{7}$ Research comparing outcomes from routine clinical CBT with the results of randomised control trials (RCTs) demonstrate that $\mathrm{CBT}$ is as effective at addressing gambling problems and related harms in real clinical contexts, as it is in research contexts. ${ }^{8}$ 


\section{FACTORS INFLUENCING THE EFFICACY OF CBT TREATMENT IN A GAMBLING CONTEXT}

The literature demonstrates that several factors have an impact on the effectiveness of CBT, including factors related to treatment structure and factors related to the client/patient group. These factors are summarised below.

\section{Treatment Factors}

\section{Type of CBT}

, CBT approaches to treating gambling problems can be divided into those that focus on exposure therapy $(E T)$ and cognitive restructuring $(C R) .{ }^{9}$

, Cognitive restructuring uses education to challenge clients' misinformed beliefs about gambling and encourages avoidance of gambling cues (audio, visual, environmental, etc.). ${ }^{9}$

, Exposure therapy breaks down the learned association between a gambling stimulus and an emotional response (e.g., excitement) through controlled experiences (e.g., seeing flashing lights of a slot machine). ${ }^{9}$

> An Australian-based randomised control trial (RCT) comparing the efficacy of exposure therapy vs. cognitive therapy, found that both modalities lead to comparable, clinically meaningful improvements in PG scores (Victorian Gambling Screen [VGS]) among treatment-seeking adults who met the criteria for problem gambling. ${ }^{10}$

> It has been recommended that CBT should incorporate elements of ET and CR, and should include regular follow-ups to detect and address relapse. ${ }^{9}$

, An Australian clinical trial found that patients who received a mindfulness intervention (e.g., breathing exercises, meditation exercises) with CBT, showed additional improvements in negative thoughts that may contribute to problem gambling (compared to those who received CBT alone). ${ }^{6}$

, Treatment was delivered weekly, face-to-face, over a 4-week period.

> A 2016 RCT (USA) found that an intervention combining Motivational Enhancement Therapy and CBT was more effective at reducing gambling problems (South Oaks Gambling Screen [SOGS]) and money spent on gambling among patients accessing substance use treatment (compared to a brief [10-15 minute] psychoeducation intervention and a brief [10-15 minute] advice intervention). ${ }^{11}$ 
, Patients received three, weekly, 50-minute sessions of CBT.

, The goal of the CBT sessions was to help patients learn to recognise what triggered their gambling and to cope with the urge to gamble.

\section{Length of Treatment}

, A 2015 meta-analysis found that treatment efficacy was not linked to number of treatment sessions or hours of treatment, and concluded that brief interventions may be impactful and practical, particularly when resources are limited. ${ }^{12}$

, A 2017 systematic review recommends 6-to-8 sessions or chapters (if self-directed) of cognitive behavioural treatment. ${ }^{13}$

\section{Treatment Setting}

> A 2015 meta-analysis found that in-person, outpatient CBT approaches seem to lead to the greatest reductions in problematic gambling behaviours (compared to inpatient or self-help settings). ${ }^{12}$

\section{Group vs. Individual CBT}

, A 2015 meta-analysis found no difference in efficacy between individual and group CBT. ${ }^{12}$

1 A Canadian controlled study found that in-person, group CBT has been found to decrease problems related to online gambling (e.g., increase sense of control over gambling, and decrease gambling severity and frequency). ${ }^{14}$

> A 2009 meta-analysis found that individual, self-directed (workbook), and group sessions were significantly associated with reduced problem gambling (assessed using various screening tools, SOGS most frequently used) three months post-treatment, but only participants in group CBT maintained reduced problem gambling after six months. ${ }^{5}$

, A 2018 matched-pair comparison study of 84 male Chinese problem gamblers demonstrated that a group cognitive behavioural intervention ( $\mathrm{CBl}$; eight sessions, three hours each) was more effective at reducing gambling behaviours, urges, cognitions (based on SOGS and Gambling Urge Scale [GUS]), and related harms (anxiety and depressive symptoms), compared to a social activity group (eight sessions, three hours each; discussed current events, planned and implemented social activities). ${ }^{15}$ 
> $\mathrm{CBI}$ sessions focused on enhancing motivations to change, exploring gambling triggers, becoming aware of false gambling beliefs, recognising negative emotions, and learning about relapse prevention.

, Negative psychological states (e.g., stress) were found to influence the relationship between the $\mathrm{CBI}$ and reductions in gambling problems.

, The authors suggest that integrating cognitive behavioural and emotional regulation components may enhance the outcomes of the intervention on gambling problems.

> Group CBT (90 minutes sessions, 16 weeks) lead to significant improvements in severity of gambling behaviour (SOGS) and psychological problems in a sample of 440 treatment-seeking patients with a gambling disorder (Spain). ${ }^{16}$

\section{Online and Self-help Formats}

> A 2017 RCT demonstrated that internet-based CBT (I-CBT; otherwise referred to as computerised CBT or CCBT) can reduce gambling urges and misinformed beliefs about gambling and improve quality of life more effectively than internet-based monitoring, feedback, and support (another form of internet-based treatment). ${ }^{17}$

, A 2018 RCT of 110 community-based Australian adults found that a gambling-specific, self-help CBT (SHCBT) manual led to improved gambling behaviours and problem gambling symptoms (Canadian Problem Gambling Index [CPGI]), as well as better mental health (depression, anxiety, and stress) and quality of life (compared to a waitlist control group). ${ }^{18}$

> A 2012 systematic review of I-CBT for treating PG found that the effects were large (based on pre-and-post data), but overall, based on the volume and quality of data available, the authors concluded that there was insufficient evidence to suggest overall efficacy of I-CBT. ${ }^{19}$

, SHCBT and I-CBT may be effective treatment options for problem gamblers who do not wish to, or are unable to, seek professional face-to-face treatment. ${ }^{18}$

> A 2017 review found that some degree of therapist support can improve outcomes of selfdirected CBT (via a workbook or internet format). ${ }^{13}$

\section{Client/Patient Factors}

\section{Severity Level}

> A study of adult men seeking treatment for gambling disorder did not find differences in CBT outcomes between patients categorised by the American Psychiatric Association's Diagnostic and Statistical Manual of Mental Disorders, 5th edition (DSM-5) severity levels. ${ }^{7}$ 


\section{Primary Gambling Activity}

> A 2009 systematic review and meta-analysis found that CBT was effective at reducing problem gambling (assessed using various screening tools, SOGS most frequently used) across primary gambling activities (at three and six-month windows, excluding scratch cards at the three-month window). ${ }^{5}$

> A 2018 study of treatment-seeking adults in London (UK) found significant differences in dropout rates depending on gambling activity. ${ }^{20}$

, Gambling on gaming machines was predictive of pre-treatment dropout (not attending treatment).

, Sports betting was predictive of drop-out once treatment had started.

\section{State of Change}

> One cross-sectional study of treatment-seeking outpatient problem gamblers in the USA showed that pre-treatment stages of change may influence treatment retention and level of psychosocial functioning throughout treatment (e.g., being in the action phase was negatively associated with retention). ${ }^{21}$

> Stages of change (precontemplation, contemplation, preparation, action, and maintenance) come from the popular Transtheoretical Model of Change, ${ }^{22}$ and refer to a person's readiness to take or maintain action toward a desired goal.

, Researchers suggested that treatment plans be adjusted to account for a patient's stage of change.

\section{Ethnicity}

> Research suggests that CBT is effective for use with diverse groups because, regardless of cultural background, it helps problem gamblers identify their own influences and beliefs about gambling. Problem gamblers can then focus on changing related thoughts and behaviours. ${ }^{23}$

> Research demonstrates that CBT can improve gambling problems and related harms for pathological gamblers of Asian descent. ${ }^{24-26}$

, A cross-sectional study of 389 pathological gamblers in Singapore found that three months after CBT treatment (eight individual sessions, plus a self-help workbook): ${ }^{24}$

, $57 \%$ of participants reported abstinence from gambling.

> All participants reported improved quality of life and significant reductions in gambling frequency and severity of problematic symptoms (Gambling Symptom Assessment Scale [G-SAS]). 
, In a retrospective chart review study of 758 South Korean outpatients being treated for gambling disorder (based on DSM-IV criteria), patients who received group CBT remained in treatment longer (i.e., were less likely to drop out) than outpatients receiving individual psychotherapy. ${ }^{25}$

> An RCT found that, among gamblers in Hong Kong, group CBT (ten sessions, three hours each) led to: ${ }^{26}$

> Fewer gambling behaviours.

, Fewer gambling-related distorted beliefs.

> Fewer depression, anxiety, and stress-related symptoms.

, A lower level of gambling urge (compared to individual counselling).

, A prospective longitudinal study found that, among Chinese gamblers, unemployment, larger than average debts, attending fewer treatment sessions, and poor treatment satisfaction predicted poorer CBT outcomes. ${ }^{27}$

\section{Gender}

, One cross-sectional study suggests that the outcomes of CBT on gambling problems are consistent across men and women. ${ }^{28}$

, In a cross-sectional study of treatment-seeking women accessing individual CBT, high levels of sensitivity to reward (which tend to encourage engagement in activities that provide immediate gratification) negatively impacted treatment compliance and risk of drop-out. ${ }^{29}$

, A 2018 scoping review suggested that individualised, abstinence-based CBT may be the best treatment option for women, particularly those with severe gambling problems. ${ }^{30}$

\section{Personality}

> A 2015 study (Spain) of the role of personality in CBT treatment found that the following characteristics predicted dropout: ${ }^{31}$

> Sensation seeking (seeking excitement and novel experiences)

, Impulsivity (acting impulsively without taking time to think)

, Neuroticism-anxiety (emotional upset, tension, low self-confidence, and sensitivity to criticism) 


\section{Comorbid Conditions}

> A cross-sectional study of UK-based PG treatment seeking adults found that CBT produced comparable outcomes (based on PGSI) for both smokers and non-smokers (i.e., no significant difference in treatment completion or outcomes). ${ }^{32}$

, Evidence suggests that CBT may be equally effective for problem gamblers with and without co-occurring mood and anxiety disorders. ${ }^{33,34}$

> A cross-sectional study of 53 treatment-seeking problem gamblers (based on DSM-IV criteria) tested the relationship between number of comorbid disorders and treatment outcomes. It found that higher numbers of co-occurring disorders were associated with high problem gambling scores (assessed using NODS-SA). ${ }^{35}$

> Participants engaged in 1 to 36 , one-hour individual therapy sessions rooted in CBT, psychotherapy, and solution-focused therapy.

> The researchers found that a patient's number of co-occurring disorders did not influence psychosocial outcomes of treatment.

\section{Other Demographic Factors}

, In a cohort study of treatment seekers with a gambling disorder, group CBT dropout rates were higher in individuals who were younger and who had lower levels of education. ${ }^{16}$

, A cohort study of treatment seeking problem gamblers (VGS) suggested that exposure-based $\mathrm{CBT}$ is well-received by gamblers with low education levels. ${ }^{36}$

> Other research shows that individuals who are younger and less educated were more likely to respond poorly to CBT treatment overall. ${ }^{16}$

> Researchers suggest that gambling treatment providers may be able to mitigate this pattern by establishing strong relationships during the initial therapy sessions. ${ }^{16}$

\section{GAPS AND LIMITATIONS}

, There is an absence of large-scale, well-controlled CBT and gambling studies with long-term follow-up. ${ }^{5}$

> Even though there is evidence to suggest that CBT is effective for treating gambling problems, a major limitation of its effectiveness is that people with gambling problems often fail to seek help. ${ }^{5}$ 
> CBT dropout is prevalent and has an impact on the findings of many included studies. ${ }^{17,28}$

> Researchers suggest that building strong therapeutic relationships in the first weeks of treatment may help patients to remain in treatment. ${ }^{16}$

\section{Conclusion}

Research demonstrates that CBT has robust, positive, short and long-term effects on problem gambling, across gambling types and severity levels. The current evidence suggests that in-person CBT may be particularly effective at addressing gambling thoughts/behaviours and related harms. Additionally, internet-based CBT (I-CBT) may be a valuable tool for treating problem gambling, particularly among those who may not otherwise seek help. While some research recommends that CBT treatment takes place over 6-8 sessions (or chapters if self-directed), there is also evidence suggesting that brief cognitive behavioural interventions can lead to positive outcomes. The literature recommends that CBT protocols include elements of both exposure therapy and cognitive restructuring. Several studies suggest CBT can lead to positive changes in gambling thoughts, behaviours, and related harms among women and BAME communities (particularly gamblers of Asian descent). Included research suggests that young people and people with lower levels of education may be less likely to respond positively to CBT, but that strong therapeutic relationships may help to mitigate this pattern. More research is needed to determine how CBT outcomes can be maximised among key, understudied groups (e.g., women, BAME communities, and young people). 


\section{Section 4 Motivational Interventions}

\section{INTRODUCTION}

This section summarises recent research on the use of motivational interventions for treating gambling problems. Motivational interventions are intended to increase people's motivation to reduce their problematic behaviours, and typically include brief interventions, motivational interviewing (MI), and motivational enhancement therapy (MET). ${ }^{13}, 37$ Recent literature speaks to the effectiveness of combining motivational interventions with CBT, and the use of motivational interventions for addressing low treatment engagement and high dropout rates.

\section{BRIEF INTERVENTIONS}

> Research shows that brief motivational interventions can be very effective at treating disordered gambling ${ }^{4}$ though effect sizes are small and somewhat inconsistently maintained. ${ }^{37}$

> Brief motivational interventions draw upon principles of $\mathrm{Ml}$ and are typically a single-session, short in length ( 20-75 minutes) and carried out in an opportunistic environment (doctor's office, school, etc.). ${ }^{37}$

, Secondary analysis of RCT data (Canada) found that goal selection at the outset of a brief motivational intervention had an impact on treatment outcomes. ${ }^{38}$

, Participants with an abstinence goal reduced their number of days gambling significantly more than participants with a moderation goal. 
> A 2016 pilot study tested the feasibility of a brief intervention (BI) for at-risk gambling (based on four-item National Opinion Research Center DSM Screen for Gambling Problems - Preoccupation, Escape, Risked Relationships, Chasing [NODS-PERC]) delivered in primary health care centres (HCCs) in Sweden. ${ }^{39}$

> Patients at the HCCs were screened for gambling problems. Those who were identified as at-risk (reported one or more items on the NODS-PERC screen) received the brief intervention.

, The brief intervention consisted of:

, Feedback on screening results.

, Information about gambling.

, Exploration of personal consequences of gambling.

, Discussion about personal reasons behind gambling behaviour.

, Findings suggest:

, BI for at-risk gambling can be delivered in primary health care settings if staff are adequately trained.

> Patients are more willing to discuss their gambling habits with their regular caregiver during a normal visit.

> Problem gambling screening tools should be carefully selected to ensure that staff and patients understand the questions and are comfortable with them.

> A 2016 RCT of problem gamblers in Canada found that a brief intervention was as effective at reducing gambling (immediately following treatment and at the 1-year mark) as 6 sessions of cognitive therapy, behavioural therapy, or motivational therapy. ${ }^{40}$

, Gambling was assessed using study-specific questions, severity of problem gambling was assessed using a checklist based on DSM-IV criteria for pathological gambling.

> The brief intervention was 90 minutes in length and focused on:

> Reviewing patient assessments.

> Providing handouts summarising behavioural, cognitive, and motivational interventions, similar to those received by patients in the other treatment groups.

> Practical, common-sense advice (also summarised in a booklet given to the patient). 


\section{Motivational Interviewing}

, $\mathrm{Ml}$ is a therapy that helps to move a client toward reducing their gambling by confirming and supporting their desire to change. ${ }^{41}$

1 A 2015 meta-analysis of the effectiveness of MI for treating disordered gambling found: ${ }^{41}$

, Ml led to modest reductions in both the number of days gambled and money lost.

, Six months following treatment, participants who received $\mathrm{MI}$ interventions still engaged in gambling less frequently than control participants, though differences in money lost were not found.

> A 2018 RCT of remote MI strategies found that, among a sample of Canadian treatment-seeking gamblers, three telephone-based motivational interviews, plus using a self-help workbook, led to significantly reduced problem gambling behaviours (assessed using PGSI) and consequences (compared to a waitlist control group). ${ }^{42}$

> The motivational phone interviews focused on participants' motivations behind changing their gambling behaviour and the advantages of doing so.

, The intervention lasted 11 weeks and outcomes were maintained up to 12 months following treatment.

, The researchers suggested that the motivational telephone interviews appeared to have specifically contributed to the success of the program.

\section{Motivational Enhancement Therapy}

, Motivational enhancement therapy (MET) is a counselling style that draws upon skills of motivational interviewing and helps patients explore and resolve ambivalence about behaviour change. ${ }^{43}$

, A 2016 RCT (USA) found that an intervention combining MET and CBT was more effective at reducing gambling problems and money spent on gambling, among patients accessing substance use treatment (compared to a brief [10-15 minute] psychoeducation intervention and a brief [10-15 minute] advice intervention). ${ }^{11}$

, The MET with CBT intervention was delivered over four, 50-minute sessions.

, In the MET session, patients received personalised feedback about the consequences of gambling, and discussed how gambling fit within their goals and value systems. 
, The MET with CBT intervention significantly reduced amounts wagered and SOGS scores in the first five months, compared to the brief advice intervention.

> From months 5 to 24, receiving MET with CBT was the only predictor of decrease in problem gambling (assessed using SOGS) in the long term.

\section{Additional Evidence for Combining Motivational Interventions with CBT}

> A 2017 systematic review of gambling treatment options found:13

, Ml alone did not consistently reduce problem gambling symptoms.

> $\mathrm{MI}$ in combination with CBT consistently produced benefits such as reduced time and money spent on gambling.

> A 2018 cohort study (Spain) demonstrated that a treatment protocol combining a motivational intervention with CBT (six months, 40-minute weekly or bi-weekly sessions), significantly improved participants' problematic gambling behaviour (assessed using NODS) and related harms (quality of life, overall impulsive behaviour). ${ }^{44}$

\section{Motivational Interventions for Enhancing Treatment Engagement}

, Motivational interventions are a proposed way to address high problem gambling treatment refusal and dropout rates. ${ }^{45}$

, The independent nature and brief time required by these approaches may be one way to encourage individuals to participate in therapeutic change. ${ }^{41}$

> A 2018 RCT (USA) found that, among treatment seekers with a gambling disorder (assessed using the Massachusetts Gambling Screen [MAGS]), receiving a personalised motivational letter (containing elements of motivational interviewing), in addition to a treatment reminder call, significantly increased a patient's likelihood of attending a first treatment session. ${ }^{45}$

> Letters included the following elements of motivational interviewing:

) Partnership (i.e., the therapist wants to work with clients to change their gambling)

> Acceptance (i.e., prioritise clients' welfare)

, Compassion (i.e., promote clients' goals and needs)

> Evocation (i.e., elicit clients' own thoughts rather than the therapist's thoughts about changing gambling) 


\section{Motivational Interventions and Bame Communities}

- A 2016 review suggests that motivational interventions are effective for use with diverse cultural groups because, regardless of cultural background, they help problem gamblers identify and address their own beliefs about gambling. ${ }^{23}$

\section{Conclusion}

There is some evidence to suggest that brief motivational interventions, and in-person and remote MI and MET can have a positive impact on problematic gambling behaviours. The literature on motivational interventions for treatment of problem gambling is somewhat limited, and the results are not particularly robust or maintained consistently over time. Brief motivational interventions may provide meaningful, resource-efficient options, and opportunities for engaging problem gamblers through environments they are already accessing and comfortable with (e.g., doctor's office). Research suggests that motivational interventions may have a strong pre-treatment application, as they are shown to enhance likelihood of attending treatment and decrease dropout. As well, a growing body of research demonstrates that motivational interventions may be particularly effective when paired with CBT. Finally, motivational interventions may be an effective option for treating problem gambling within BAME communities, as they facilitate a process of identifying and addressing gamblers' own influences and beliefs about gambling, in a way that adapts to reflect cultural backgrounds and belief systems. 


\section{Section 5 Remote and Self-help Interventions}

\section{INTRODUCTION}

This section covers the literature on remote and self-help interventions that draw upon multiple treatment modalities. These interventions are growing in popularity ${ }^{4}$ and are proposed as cost-effective, anonymous, and convenient options for reducing barriers and enhancing access to treatment, for those who may be unlikely or unable to use face-to-face treatment options. ${ }^{46-48}$

\section{INTERNET-BASED INTERVENTIONS}

, A 2014 systematic review concluded that the evidence on the effect of internet-based interventions for treating gambling problems is inconsistent. ${ }^{49}$

> However, a 2016 systematic review of internet-based interventions for addictions found that, in the case of problem gamblers, internet-based interventions led to significant reductions in gambling behaviour. ${ }^{46}$

> Additionally, a more recent scoping review (2019) found that internet-based interventions effectively address gambling problems by reducing: ${ }^{47}$

, Overall problem gambling scores (assessed using different screening tools in different studies)

, Problematic gambling behaviours (e.g., time and money spent)

> Anxiety, depression, alcohol consumption, and overall distress 
> The most commonly used online therapeutic modalities are CBT and motivational interventions. However, a 2011 review suggests that a blend of modalities may be appropriate for internetbased interventions. ${ }^{50}$

> Two systematic reviews suggest that that some degree of engagement with a therapist (via mobile phone, email, text message, or telephone) may improve the effectiveness of internetbased treatments. ${ }^{46,50}$

, A 2019 RCT of adult problem gamblers (based on PGSI) in Canada found that online, selfdirected treatment options reduced days of gambling and problem gambling severity (at 3 and $12-$ month follow-ups). ${ }^{51}$

, The study compared outcomes of an extended online gambling intervention to a brief online personalised feedback intervention.

> The extended intervention included a series of online self-assessment activities, and cognitive and behavioural strategies for addressing gambling problems.

> The brief intervention included a brief assessment, a comparison of individual results to societal norms, and brief advice for reducing or stopping gambling.

, The outcomes of the two interventions were both positive and not significantly different.

\section{Internet-based Interventions and Comorbid Conditions}

> A 2016 systematic review found that internet-based interventions decreased gambling and related harms among problem gamblers with severe anxiety and depression. ${ }^{46}$

> A German RCT of 140 adult (18-65 years) slot machine players investigated whether an online treatment program called Deprexis helped treat depression and improve gambling behaviour in slot machine gamblers with gambling disorder. ${ }^{52}$

, The Deprexis program consisted of 10 modules, all based on cognitive behavioural therapy.

> Participants who completed Deprexis had fewer symptoms of depression and problem gambling after the intervention period (PG assessed using the Yale-Brown Obsessive Compulsive Scale Modified for Pathological Gambling [PG-YBOCS] and SOGS; compared to waitlist control group).

, Participants with severe depression, and those who gambled to escape loneliness, appeared to benefit most from the Deprexis program.

> Results suggest that an online intervention program that focuses on underlying mental health issues, may help reduce depression and gambling problems in gamblers. 


\section{Internet-based Interventions and Demographic Factors}

> Several reviews demonstrate that internet-based problem gambling treatment can be particularly effective for women. ${ }^{47,}, 50$

, One review suggests this may be because internet-based interventions provide opportunity for female-only treatment and discussion groups, which may be more comfortable for some women. ${ }^{3}$

> A 2016 cohort study (Canada) investigated the effectiveness of webinar-based group counselling and a tutorial workbook for women with gambling problems (assessed using DSM-IV and CPGI). ${ }^{53}$

, Twelve group counselling webinar sessions were offered over three months. Participants were asked to complete one tutorial workbook module per week and participate in webinar discussions.

, Each counselling webinar started with mindfulness meditation.

> After participating in the treatment, women reported:

, Gambling less frequently

> A decreased urge to gamble

> An increased awareness of their gambling triggers and behaviours

, Increased happiness and hopefulness about the future

> Feeling less alone in their gambling problems and an increased sense of wellness

> A 2015 RCT tested the effectiveness of a computer-based personalised normative feedback (PNF) protocol for addressing gambling problems among college students who self-reported at least some gambling problems (assessed using SOGS). ${ }^{54}$

, Participants who completed the PNF received summary information about their own gambling habits (frequency, expenditure, and time spent), their perception of their peers' habits, actual gambling norms among their peers, and a percentile ranking of their gambling compared to their peers'.

, Compared to the control group, PNF participants experienced a significant reduction in their gambling problems (assessed using SOGS). 


\section{Self Help Interventions}

> A pragmatic clinical trial assessed the effectiveness of a tutorial workbook (TW) for helping Canadian women with gambling problems (assessed using DSM-IV and CPGI) make gamblingrelated changes. ${ }^{55}$

, The workbook contained 12 modules that helped women to explore whether their gambling was a problem, establish gambling-related goals, and address relapse prevention strategies. It also focused on issues underlying gambling urges, and taught mindfulness, stress management, and emotion regulation.

, Most women reported:

> The TW helped them modify gambling behaviours through increased understanding and awareness of their gambling triggers.

, Feeling better about themselves, improved mood and anxiety levels, feeling less isolated, and positive changes in their relationships.

1 Results suggest that the TW can be used as a treatment resource for women gamblers, who may face barriers to accessing other treatment. ${ }^{55}$

> A 2015 RCT (USA) compared the treatment outcomes (during treatment and one year later) of a self-help workbook alone (WB only) and self-help workbook with some guidance from a therapist $(\mathrm{WB}+\mathrm{G}) .^{56}$

, Participants met at least two DSM-IV criteria for pathological gambling.

, All participants worked through the workbook over a 20 -week period, and the WB+G met with a psychologist for $45-50$ minutes, five times over the course of the 20 weeks.

> Fewer participants in the $W B+G$ group gambled during treatment and at follow-up, compared to the WB only group.

, The WB only group reported spending less money on gambling during treatment, compared to the start of the treatment, but this effect was not maintained at one-year follow-up.

, Both groups reported fewer gambling-related symptoms (using Gambling Symptom Assessment Scale [GSAS]) during treatment and at follow-up (e.g., gambling urges and thoughts).

, Reduction in gambling-related symptoms occurred more quickly with therapist guidance. 


\section{Research Recommendations}

, More randomised studies are needed to determine the effects of remote interventions on gambling problems. ${ }^{49}$

, A 2016 report on internet-based interventions by the Australian Gambling Research Centre recommends: 48

, Providers offer remote interventions to help reach under-served populations and those who may not otherwise seek help (e.g., young people, women, and those who face timing barriers, such as employment or childcare).

, Remote interventions be offered in community, treatment, and gambling settings (online, in venue, etc.).

> Providers target their promotion of remote interventions to attract new help-seekers.

, Remote interventions should be integrated and offered across a range of modalities.

\section{Conclusion}

Remote and self-help interventions appear to reduce problem gambling and related harms. The most common modalities used in an online context are motivational interventions and CBT, but research suggests that a blend of modalities might be most appropriate. Though included approaches vary considerably, commonalities between effective remote interventions appear to be self-direction, cognitive behavioural and motivational techniques, goal setting, some degree of relationship/interaction with a clinician, and access to information about normative behaviours for purposes of comparison. Online and remote interventions can be particularly useful for women and other groups who may face barriers, or who may be less likely to access face-to-face treatment. Overall, research suggests that remote and self-help interventions may provide an important opportunity to enhance treatment and support uptake, and reduce problem gambling. However, more research is needed to determine which combination of factors (length, modality, degree of clinician support, etc.) may lead to the most robust treatment outcomes. 


\section{Section 6 Helplines}

\section{INTRODUCTION}

This section summarises recent research on helplines for addressing problem gambling. Gambling helplines are often offered as the first point of support for gamblers. They offer information and referrals to formal treatment services and may also provide support and brief interventions. Helplines are advantageous, as they are cost effective, easily accessible, and confidential. ${ }^{57}$

\section{GENDER DIFFERENCES AMONG HELPLINE CALLERS}

, Secondary analysis of helpline data explored gender patterns among 150 first-time gambling helpline callers in New Zealand. Callers received standard helpline care lasting an average of 33 minutes and then were followed up with at 3,6 , and 12 months after their call. The study found:

, Women reported more severe gambling problems (based on PGSI), greater emotional distress, and lower quality of life than men.

, Women were more likely to report electronic gaming machines as their most problematic form of gambling.

> Despite reporting lower gambling severity (based on PGSI), men were more likely to seek formal treatment and attend Gamblers Anonymous following the call (compared to women).

, Both women and men had significant improvements in gambling behaviour, emotional well-being, and quality of life after their contact with the helpline. 
> Another analysis of gambling helpline data (USA) found: ${ }^{58}$

, Most helpline callers were women.

, Men and women were equally likely to initiate treatment following their call.

\section{Brief Interventions Via Gambling Helplines}

> A three-year prospective study of 131 callers to the New Zealand national gambling helpline evaluated the impact of the helpline's standard care intervention on problem gambling and depression over three time points (immediately following the intervention, one year after, and three years after the intervention). ${ }^{59}$ The study found:

, PGSI scores dropped steadily after the intervention (from an average of 17 points in the initial assessment, to 9 and 7.5 points at the one and three-year follow ups, respectively).

> Depression levels also dropped, following a similar pattern to PGSI scores (74\% had depression at initial assessment, compared to $42 \%$ at the one-year follow-up, and $41 \%$ at the three-year follow-up).

> Analyses showed that the reduction in gambling problems following the helpline intervention were directly related to a reduction in depression.

, A 2014 systematic review found no consistent evidence for a positive effect of helpline interventions on gambling. ${ }^{49}$

\section{Gambling Helplines and Treatment Initiation}

, Interviews with helpline callers demonstrated callers are more likely to access treatment after a helpline call if they have positive views about treatment, believe they will be able to relate to other treatment seekers, and recognise they have a gambling problem. ${ }^{60}$

, Helpline counsellors should be aware of these motivators for treatment-seeking and should encourage problem gamblers to follow through with referrals to treatment programs.

> Analysis of gambling helpline data (USA) found that, among 554 included callers, those who referenced family or financial problems as their reason for calling were more likely to initiate treatment. ${ }^{58}$ 
, Through comparing their findings to similar research, ${ }^{61}$ the authors suggest that having helpline staff schedule an appointment with a counsellor before ending the call may improve the likelihood that a caller attends their first treatment session (compared to giving a referral number to the caller).

\section{Conclusion}

The research on gambling helplines as a form of treatment and as a pathway to treatment is somewhat mixed. The included evidence suggests that helplines may be a good resource for supporting women, who may otherwise be less likely to engage with problem gambling support. The results of one study suggest that offering a brief intervention via a gambling helpline may help to immediately reduce problem gambling and related mental health symptoms, though this idea was not supported by the findings of a review on the topic. ${ }^{49}$ Evidence also suggests that helplines may be an important pathway to further treatment, and that having helpline staff book a caller's initial appointment with a treatment provider may help to increase that caller's likelihood of attending further treatment. 


\section{Section 7}

Treatment Involving

Concerned

Significant Others

\section{INTRODUCTION}

This section summarises research on engaging concerned significant others (CSOs) (also commonly known as affected others) in problem gambling treatment. Problematic gambling does not only harm the individual gambler, but also CSOs in their lives. Similar to gamblers, CSOs may undergo stress, financial difficulties, poor mental health, and other negative consequences. ${ }^{62}$ This chapter will cover treatment protocols that engage CSOs in gambling treatment.

\section{ENGAGING CSOS IN TREATMENT DESIGNED FOR PROBLEM GAMBLERS}

, A non-randomised comparison study of men with a gambling problem (assessed using SOGS and DSM-IV ) investigated if patients receiving care in a Gambling Disorder Unit were more likely to recover if CSOs were involved in their therapy sessions. ${ }^{63}$

, All patients received the same cognitive behavioural therapy for 16 weeks. Gamblers in the CSO group had a CSO join them for 7 of the 16 therapy sessions.

, Patients with CSOs attending therapy sessions:

, Had fewer psychological problems after the treatment had ended.

, Were more likely to attend therapy sessions.

> Were less likely to drop out of therapy. 
, Patients who had a spouse or partner attend some of their therapy sessions were more likely to follow treatment guidelines, and less likely to relapse, compared to clients who had non-spousal others join them.

\section{Treatment Designed for Both Problem Gamblers and Their CSOS}

, A pilot RCT in Sweden compared the outcomes of cognitive behavioural therapy (CBT) with the outcomes of behavioural couples therapy (BCT) for 18 problem gamblers (PGSI) and their concerned significant others (CSOs). ${ }^{64}$

, Both treatments were delivered online with therapist support.

, Immediately following treatment and at follow-up, gamblers in both groups improved in terms of gambling severity (assessed using NODS), money lost to gambling, and symptoms of anxiety and depression.

, CSOs in the BCT group also had reduced symptoms of depression and anxiety after treatment and at follow-up.

> Results suggest that BCT is a promising treatment for problem gambling, but further research is needed to explore its long-term effects.

> A Canadian pilot RCT tested treatment outcomes of Congruence Couples Therapy (CCT) for pathological gambling (assessed using DSM-IV-TR). ${ }^{65}$

, CCT is an emerging therapeutic modality that works with pathological gamblers and their spouses jointly as an integrated system.

, Couples in the treatment group received 12 weekly sessions of CCT (face-to-face or online).

> Results show that the CCT group improved significantly in terms of gambling symptoms, mental health distress, and spousal functioning (compared to the control group).

> A randomised clinical pilot study in Canada compared the experiences of pathological gamblers (assessed using The World Health Organization World Mental Health Composite International Diagnostic Interview [WHM-CIDI]) and their partners after receiving couple or individual therapy. ${ }^{66}$

, Participants in the couple therapy group received Integrative Couple Treatment for Pathological Gambling (ICT-PG).

, In the case of individual therapy participants, gamblers received the usual treatment for pathological gambling, and their partners attended family member services that helped them to care for their own wellbeing, and to better understand gambling disorder. 
, Participants reported satisfaction with both treatment types, but their experiences were more positive in couple therapy.

, Gamblers favoured individual treatment if they had a great deal of difficulty talking about their gambling problems in front of their partners.

, The couples in couple therapy reported that this treatment type helped them develop better communication skills and mutual understanding.

\section{Treatment Designed for CSOs Only}

- A Canadian randomised clinical trial examined if the Community Reinforcement and Family Training (CRAFT) approach could support CSOs of pathological gamblers (based on DSM-IV criteria). ${ }^{62}$

, CRAFT emphasises the CSOs personal wellbeing and teaches CSOs skills for reinforcing non-gambling behaviours, avoiding negative reinforcement, and withholding reinforcement for gambling behaviours.

, Thirty-one CSOs received either an individual intervention with a therapist (8-12 one-hour sessions) or a self-help workbook, both based on the CRAFT approach.

> Results show that the CRAFT approach delivered face-to-face by a therapist might be more successful at reducing money gambled compared to a self-help workbook.

\section{Conclusion}

Many of the included studies on engaging CSOs in problem gambling treatment are pilot studies and more, larger research studies are needed to truly determine the efficacy of the modalities included here. However, the evidence shows that problem gamblers who have a concerned significant other, such as a spouse, sibling, parent, or loved one, as part of their treatment sessions, may have better treatment outcomes. Engaging a spouse in treatment (rather than a parent, sibling, or other CSO) may be particularly impactful. Also, pilot results suggest that several modalities designed to treat both the person who gambles and their spouse/partner, may be particularly effective at reducing harm experienced by both parties. Specifically, research supports the use of online behavioural couples therapy and 12 weekly sessions of congruence couples therapy delivered online or in-person. 


\section{Section 8 Residential Treatment}

\section{INTRODUCTION}

This section summarises recent research on residential treatment for problem gambling. Being immersed in a supportive environment, away from day-to-day challenges and stressors, can be beneficial for some clients. Residential treatment may be a particularly appropriate option for patients with complex needs and comorbid conditions. ${ }^{67}$

\section{PROFILE OF PATIENTS ACCESSING RESIDENTIAL TREATMENT}

, A multi-sample comparison study of inpatient and outpatient gambling treatment seeking adults in Italy, found that those seeking inpatient (residential) treatment, demonstrated more severe gambling problems (assessed using SOGS) and higher levels of: 68

, Dissociation (disconnecting from surroundings and/or self)

, Attention impulsiveness

> Difficulty in identifying feelings

, Externally oriented thinking 
, A survey study of adults accessing substance use disorder treatment in the USA found high rates (21\%) of lifetime disordered gambling (assessed using SOGS) among participants. ${ }^{69}$

, Though more than a quarter of patients who met the criteria for disordered gambling recognised their gambling needed to be addressed, many had never accessed self-help (84\%) or support (82\%) for their gambling problems.

> A mixed-methods evaluation of residential treatment services in Germany (1998-2011) found:70

, $1 \%$ of problem gamblers access residential treatment

, $11 \%$ of residential treatment seekers were women

, The peak age for accessing residential treatment was higher among women (40-49 years) compared to men (30-39)

, $93 \%$ of residential treatment seekers had at least one comorbid disorder

\section{Treatment Pathways}

2. The same German study found the top four pathways into residential care included: ${ }^{70}$

, Counselling centre

, Other inpatient facility

, Self-referral

, General practitioner

\section{Residential Treatment Outcomes}

, In a pilot study of 53 adults in Australia, predictive models showed that an inpatient gambling treatment program predicted significant improvement in gambling indicators over the 12 months following treatment. Gambling indicators included problem gambling (Victoria Gambling Screen [VGS]), the Kesler 10 Scale (K10), and the Work and Social Adjustment Scale (WSAS) (K10 and WSAS used to reflect problems caused by gambling). ${ }^{67}$

> The inpatient (residential) program was developed to support patients whose needs are too complex for typical outpatient care.

, The program is two-weeks long and takes place in a hospital setting. 
, Inpatients participate in CBT with an emphasis on cue exposure, toward a goal of eliminating the urge to gamble.

, Inpatients also have access to allied health services in the hospital (e.g., neurology, social work, dietician, financial aid, etc.).

, Given the small sample size and challenges related to follow-up engagement, findings should be considered exploratory.

- A prospective follow-up study of 396 adults with a gambling disorder (assessed using SOGS) (Germany) evaluated the effects of inpatient treatment on gambling disorder symptoms, abstinence, and continued engagement in gambling without harmful consequences. ${ }^{71}$

, The treatment was provided at eight different sites and did not follow any specific treatment manual, but included group and individual psychotherapy, and allied supports (e.g., physiotherapy, sports therapy, nutritional counselling, and social and creative therapies).

, The average treatment duration was 76.5 days and the primary goal of treatment was to establish complete abstinence from gambling.

, All patients showed less social and family difficulties following treatment.

, One year after receiving treatment, over half of the patients continued to gamble, but half of these individuals continued gambling without having symptoms of GD (assessed using SOGS and a structured clinical interview for problem gambling [SCI-PG] based in DSM-IV criteria).

> Patients who abstained from gambling:

, Had fewer work-related difficulties.

> Had less mental distress (compared to those who relapsed and continued to experience GD symptoms).

> Showed decreases in tendencies toward anxiety, self-doubt, and other negative feelings (neuroticism), and increases in social engagement and interest (extraversion), and self-control, responsibility, and reliability (conscientiousness).

> Results suggest patients may benefit most if they abstain from gambling, but abstinence is not a necessary goal for every gambling disorder patient. ${ }^{71}$ 


\section{Predictors of Treatment Dropout}

, Secondary analysis of clinical data representing 658 men seeking residential gambling treatment in the UK found no difference in treatment dropout rates between severity groups (based on

PGSI), but found the following characteristics predicted elective dropout: ${ }^{72}$

> Age $26+$

, Higher (vs. lower) level of education

> Higher (vs. lower) debt

, Poker playing and online gambling

, Choosing a shorter treatment program (3-6 months vs. 9 months)

> Depression

, Childhood adversity (e.g., parental divorce, violence, abuse, bullying)

> The same study found the following characteristics predicted enforced dropout from treatment: ${ }^{72}$

> Lifetime homelessness

> Sports betting

, Smoking

> Depression

, Choosing a shorter treatment program (3-6 months vs. 9 months)

\section{Conclusion}

Recent research on residential treatment for problem gambling is minimal, and more research is needed to determine what factors enhance the efficacy of this form of treatment (e.g., length of stay, treatment modalities and allied services included, etc.). As residential treatment is often used for patients with particularly complex needs, research recommends that residential treatment providers adopt evidencebased practices and procedures for treating individuals with co-occurring disorders. ${ }^{69}$ Also, as with other forms of gambling treatment, dropout is a considerable concern raised by researchers in this area. Treatment providers might consider developing tailored interventions to reduce dropout among identified risk groups. ${ }^{72}$ 


\section{Section 9}

Pharmacological Treatments

\section{INTRODUCTION}

This section summarises recent evidence on the efficacy of pharmacological treatments for problem gambling. To date, no drug has been approved for the treatment of problem gambling. ${ }^{73}$ The evidence on pharmacological problem gambling treatments includes studies on dopamine antagonists, opioid antagonists, selective serotonin reuptake inhibitors (SSRIs), and glutamatergic agents. ${ }^{74}$ Apart from extreme cases, pharmacological treatments are not currently used for treating gambling problems in Great Britain.

\section{DOPAMINE ANTAGONISTS}

, Dopamine antagonists help to regulate bodily responses to pleasure and reward. ${ }^{3}$

, A US-based single-blind study of the efficacy of Ecopipam for treating gambling disorder, found that treatment was associated with significant reductions in problem gambling symptoms (PG-YBOCS) among 28 participants with a gambling disorder. ${ }^{75}$

, 22 participants completed the 8-week trial

, Treatment lasted eight weeks in total, one-week placebo lead-in, six weeks of medication, one-week of follow-up

, Medication doses ranged from 50 to $100 \mathrm{mg} / \mathrm{d}$ as needed

, A 2019 review of clinical trial evidence found that Olanzapine was no more effective than a placebo at addressing gambling disorder. ${ }^{74}$ 


\section{Opioid Antagonists}

, Opioid antagonists work by blocking the binding of opioids produced by the brain, interrupting the reward system that can reinforce gambling problems.

, A 2018 meta-analysis of placebo-controlled studies on drug treatments for problem gambling found that opioid antagonists worked better than a placebo in reducing gambling problems. ${ }^{76}$

, Naltrexone is suggested to demonstrate the most potential as a drug treatment for problem gambling. ${ }^{77}$

, A 2018 case series of 14 patients with severe gambling problems (assessed using the PGSI) attending the National Problem Gambling Clinic (UK), examined the effects of naltrexone as a treatment for problem gambling. ${ }^{77}$

, Patients received $25 \mathrm{mg}$ of naltrexone per day for three days, and then $50 \mathrm{mg}$ of naltrexone per day for six weeks (patients were also accessing other gambling support services throughout, such as Gamblers Anonymous).

, Of the ten participants (eight men, two women; age 29-56):

> All had reduced cravings to gamble after six weeks of treatment.

, Six were able to give up gambling completely for the duration of the study, but one relapsed after the study period.

> Four were not able to give up gambling, but gambling behaviour was reduced among two.

, Patients reported several side effects including:

, Loss of appetite

, Gastrointestinal pain

, Headaches

> Sedation

> Dizziness

, Vivid dreams 
> A 2016 RCT evaluated to effectiveness of as-needed naltrexone and regular psychosocial support for treating problem gambling (based on PG-YBOCS). ${ }^{73}$

, 101 participants who scored a 5 or higher on the South Oaks Gambling Screen-Revised (SOGS-R) were randomised (1:1) into a treatment or control group.

> Participants in the treatment group self-administered $25 \mathrm{mg}$ of naltrexone as needed, up to once daily, typically when experiencing a strong urge to gamble or planning to gamble, and tracked their medication use in a diary.

, Control group participants followed the same protocol but self-administered a placebo instead of a dose of naltrexone.

, All participants also received psychosocial support over three appointments with a psychologist.

, Researchers found no significant differences in problem gambling outcomes (assessed using the PG-YBOCS), between the group that received as-needed naltrexone and the group that received a placebo.

> A more recent (2019) review of clinical trial evidence found that both naltrexone and nalmefene significantly reduced gambling disorder symptoms, though each drug was only represented in two clinical trials. ${ }^{74}$

\section{SSRIs}

> A 2019 review of clinical trial evidence suggests research on the effectiveness of SSRIs for treating gambling disorder is mixed. Patients with comorbid Major Depressive Disorder or Obsessive-Compulsive Disorder, may be more likely to respond to this form of treatment. ${ }^{74}$

\section{Glutamatergic Agents}

> Glutamatergic agents are proposed to interrupt pleasure and reinforcement processes associated with gambling problems. ${ }^{3}$

> A 2015 systematic review of clinical trials using N-acetyl cysteine (NAC) concluded that NAC did not appear to be effective for treating pathological gambling. ${ }^{78}$

, A 2019 review of clinical trial evidence found that NAC alone showed strong efficacy over a placebo for treating gambling disorder. NAC coupled with psychotherapy was associated with reduced problematic gambling symptoms among patients with a gambling disorder and nicotine dependence. ${ }^{74}$ 
> A 2017 RCT tested the effectiveness of topiramate combined with CBT for the treatment of gambling disorder. ${ }^{79}$

, 38 participants with a gambling disorder (defined as meeting 4+ DSM-5 criteria) were randomised into a treatment or control group.

> The treatment group received topiramate for 12 weeks. Doses were adjusted up to $300 \mathrm{mg} /$ day as needed over the first 8 weeks and maintained for the final four weeks.

, The control group followed the same protocol but received a placebo instead of topiramate.

- All participants also participated in four sessions of CBT with a therapist and used a workbook designed specifically for cognitive restructuring for gambling disorder.

> Researchers found that participants in the treatment group experienced a greater reduction in gambling symptoms (assessed using PG-YBOCS, the Gambling Symptom Assessment Scale [G-SAS], and the Gambling Beliefs Questionnaire [GBQ]) compared to participants in the control group.

- A 2018 meta-analysis of placebo-controlled studies on drug treatments for problem gambling found that topiramate worked better than a placebo in reducing gambling problems. ${ }^{76}$

> A more recent (2019) review found that topiramate was not effective at addressing gambling disorder. ${ }^{74}$

\section{Conclusion}

While the evidence for using pharmacological interventions to treat gambling problems is somewhat inconclusive, some studies demonstrate promising effects. Further research is needed to determine the efficacy of these interventions. Specifically, placebo-controlled, double-blind studies are needed to determine which pharmacological treatments are effective for addressing gambling problems. ${ }^{75}$ Also, research studies could further explore the effectiveness of pharmacological treatments over a longer period of time, especially after patients complete treatment. ${ }^{77}$ 


\section{Section 10} Brain Stimulation

\section{INTRODUCTION}

This section summarises research on using brain stimulation for the treatment of problem gambling. Non-invasive brain stimulation techniques used for treating addiction typically include: transcranial magnetic stimulation (TMS), transcranial direct current stimulation (tDCS), and continuous theta burst stimulation (cTBS). ${ }^{80,81}$ Each procedure involves stimulating different parts of the brain using devices on or above the scalp. ${ }^{80,81}$ Although current evidence is minimal and somewhat inconclusive, some evidence suggests that brain stimulation may have a positive effect on craving reduction/desire to gamble, gambling reinforcement, and cognitive function among problem gamblers. Outside of extreme cases, treatment involving brain stimulation is not currently used for treating gambling problems in Great Britain.

\section{CRAVING REDUCTION}

> A 2017 randomised sham-controlled crossover study (France) tested the effectiveness of repetitive transcranial magnetic stimulation (r-TMS) for addressing gambling cravings and behaviours. ${ }^{82}$

, Treatment involved one, 20.5-minute session of r-TMS over the left dorsolateral prefrontal cortex (DLPFC).

> 22 treatment-seeking participants with a gambling disorder (based on DSM-5 criteria) received a real or "sham" (fake) treatment one week and the other type of treatment the following week.

> Participants rated their gambling craving before and after watching a 2.5 -minute video specific to their preferred gambling type (e.g., sports betting, casino, horse racing, etc.). 
, Participants also reported their gambling behaviour prior to treatment and the week following treatment, using the PG-YBOCS.

> Researchers found that r-TMS treatment significantly decreased gambling cravings compared to the sham treatment but found no significant effect of $r$-TMS on gambling behaviour.

> A sham-controlled study of nine community-recruited, non-treatment seeking, male pathological gamblers (as per National Opinion Research Center DSM Screen for Gambling Problems [NODS]) tested the effect of $\mathrm{r}-\mathrm{TMS}$ and continuous theta burst stimulation (c-TBS) on gambling reinforcement. ${ }^{81}$

, Researchers found:

> A single session of rTMS did not reduce delay discounting behaviour (placing higher value on immediate rewards compared to longer-term rewards) compared to the placebo treatment, but did reduce the participants' desire to gamble.

> A single session of cTBS to the DLPFC reduced participants' blood pressure, which would normally increase in response to play.

, A 2018 randomised, sham-controlled crossover trial (France) tested low frequency DLPFC rTMS for decreasing cue-induced gambling cravings. ${ }^{83}$

, Thirty patients seeking treatment for pathological gambling (based on DSM-IV criteria) received one real and one sham (fake) r-TMS treatment, with a 7-14-day window in between.

> At each treatment, patients would complete physiological measures and assessments of their gambling cravings, experience exposure to five minutes of visual and audio gambling cues specific to their preferred gambling activity and medium (online vs. offline), and receive r-TMS or sham treatment.

> Researchers failed to demonstrate the efficacy of DLPFC rTMS for decreasing cue-induced gambling cravings.

\section{Cognitive Function}

> A 2018 systematic review found that rTMS and tDCS enhanced cognitive functioning among individuals experiencing addiction, including gambling addiction. ${ }^{80}$ 


\section{Conclusion}

Research on the use of brain stimulation for treating gambling problems is somewhat inconclusive and subject to several limitations, including small sample sizes, inconsistencies in study design and treatment protocols, and lack of information about the mechanisms of action and change. ${ }^{84}$ Future research on brain stimulation should include large, demographically representative samples, ${ }^{81,83}$ and should investigate the long term effects of brain stimulation, ${ }^{83}$ especially whether multiple sessions can decrease problem gambling symptoms for a longer period of time. ${ }^{82}$ 


\section{Section 11 Gamblers Anonymous}

\section{INTRODUCTION}

This section summarises recent research on Gamblers Anonymous (GA) for the treatment of gambling problems. Gamblers Anonymous is a 12-step, peer-support program designed to help people maintain abstinence from gambling.

\section{GA STURUCTURE AND CONTENT}

> A UK-based study (2019) observed 20 GA meetings and summarised key themes related to the structure and content of the meetings: ${ }^{85}$

> Far more men attended GA meetings than women (only 4 of 278 observed individuals were women).

, Gamblers self-identified as compulsive gamblers and often spoke about money problems at GA meetings.

, Members often spoke about the important role that meeting attendance plays in their recovery.

> Members supported each other outside of meetings, primarily by text message.

, Many members had comorbid mental health problems and suicidal thoughts, though GA meeting chairs suggested they are not trained to deal with members' mental health problems. 


\section{Combining GA with Other Treatment Modalities}

> A 2016 review of research on GA found that evidence on its effectiveness as a treatment is inconclusive, and that GA in combination with another treatment modality (i.e., CBT) appeared to be more effective at reducing problem gambling and related harms. ${ }^{86}$

> A 2014 study found that, among Gambler's Anonymous (GA) participants, a stress management program lead to significant decreases in stress, depression, and anxiety, and significant improvements in quality of life and daily routines (compared to GA on its own). ${ }^{87}$

, The stress management program involved:

, Education regarding reward-seeking behaviours, maladjusted beliefs, dysfunctional thoughts, and coping skills.

, Instructions on eating habits, physical training, and daily routine.

, 8 weeks of at-home progressive muscle relaxation and relaxation breathing (25 minutes, $2 x$ per day), guided by an audio CD.

\section{Conclusion}

There is little recent research on the efficacy of Gamblers Anonymous for treating gambling problems. Available evidence suggests that GA is most accessed by men and that GA may not be an appropriate option for the management of comorbid mental health challenges. The findings of two recent studies suggest that GA might be most effective when paired with another treatment modality (CBT or stress management). Overall, more robust and long-term research is needed to determine whether GA on its own can lead to strong problem gambling treatment outcomes. 


\section{Section 12 Emerging Treatment Modalities}

\section{INTRODUCTION}

This section summarises recent literature on problem gambling treatment modalities that are novel and/ or somewhat under-explored within the search parameters. Each of the treatment modalities covered here require more exploration to determine overall efficacy but provides insight into potential new and innovative problem gambling supports.

\section{COGNITIVE REMEDIATION}

> A 2017 review suggests that cognitive remediation could be used to address impaired mental skills and self-control in gambling disorder patients. ${ }^{88}$

> Authors suggest that Cognitive Remediation Therapy (CRT) be used alongside usual treatment, such as CBT, to improve treatment effects.

\section{Cognitive Bias Modification}

, A recent German pilot RCT of adults with problem/pathological slot machine gambling (assessed using SOGS) demonstrated that participating in an approach avoidance training task had no unique effect on gambling-related symptoms (compared to a control group). ${ }^{89}$

, The approach avoidance task uses a software that has participants view a series of photos, including slot machines and other photos. Participants in the experimental group were required to "push" slot machine photos away and "pull" other photos in (using their mouse). 
, This finding related to problem gambling opposes findings from similar studies that support the use of cognitive bias modification for addressing challenges related to substance use.

\section{Psychodynamic Therapy}

> A naturalistic study of recovering gamblers suggests that addressing levels of anxiety and depression is critical to treating gambling problems. ${ }^{90}$

, A retrospective analysis of pilot study data (UK) evaluated a brief psychodynamic therapy treatment protocol for problem gambling patients with co-occurring mental health and addiction problems, and early-life difficulties. ${ }^{91}$

, Psychodynamic therapy aims to treat the underlying emotional issues and conflicts that might have triggered a person's gambling addiction.

> Among 78 problem gambling treatment-seekers, the protocol successfully treated problem gambling (assessed using PGSI) and reduced patients' levels of depression and anxiety.

\section{Arts-based Group Treatment}

> A 2019 Canadian pilot study evaluated an eight-week, arts-based treatment program for women with experiences in gambling. ${ }^{92}$

, The program followed a patient-centered approach in which women worked with facilitators, and each other, on a variety of visual and musical works.

, Women reported the program:

, Helped them build community connections.

, Gave them new options to manage life challenges.

> Shifted their views of themselves in a positive way.

> Fostered a sense of belonging to a community. 


\section{Conclusion}

This section provides a brief evidence base for emerging or under-researched treatment modalities that may have the potential to treat problem gambling and related harms. Researchers and treatment providers may want to continue to explore the application of these modalities, particularly in terms of targeting underserviced populations (e.g., women and gamblers with co-occurring mental illnesses). 


\section{Section 13 \\ Discussions and Conclusions}

\section{DISCUSSION}

Cognitive behavioural therapy (CBT) remains the problem gambling treatment modality with both the largest evidence base and the most compelling evidence to suggest its efficacy. ${ }^{3,12,13}$ Research demonstrates that CBT can have robust short-term and longer-term effects on problem gambling and related harms (e.g., quality of life, emotional wellbeing), ${ }^{5,6}$ across gambling types, ${ }^{5}$ severity levels, ${ }^{7}$ and demographic groups. ${ }^{23,28}$ CBT appears to be most effective when delivered in-person and in an outpatient setting. ${ }^{12}$

While the evidence supporting the use of CBT for treating gambling problems is compelling for those who attend treatment, research shows that one of the biggest barriers to overall treatment effectiveness is that people with gambling problems rarely seek treatment. ${ }^{60,93}$ Many problem gamblers experience and/or perceive barriers to treatment, and these barriers can have a significant, negative impact on a person's likelihood of accessing treatment. ${ }^{60}$ Helplines, ${ }^{60}$ motivational interventions, ${ }^{45}$ remote interventions, ${ }^{46-48}$ and self-help interventions ${ }^{55}$ may also play an important role in problem gambling treatment strategies, as they all demonstrate the potential to promote treatment uptake, even among groups who are typically less likely to access treatment.

Recent research on problem gambling helplines suggest that these resources may offer an important pathway to further treatment, particularly for women. ${ }^{57,58,60}$ The included research highlights two factors that may increase the likelihood of a helpline caller accessing further treatment. First, helpline staff may more effectively transition a caller to treatment if they book the appointment on the caller's behalf before the call is ended, rather than passing along a referral number. ${ }^{58}$ Second, helpline staff should be aware of key motivators for treatment initiation among helpline callers, and should encourage follow through with treatment referrals. ${ }^{60}$ These motivators include callers having positive views about treatment, believing they will be able to relate to other treatment seekers, and recognising they have a gambling problem.

Motivational interventions may have a strong pre-treatment application, as they are shown to enhance the likelihood of attending treatment. ${ }^{41,45} \mathrm{~A}$ growing body of research demonstrates that combining motivational 
interventions with CBT may be particularly effective for reducing gambling problems and related harms. ${ }^{11}$, 13, 44 Motivational interventions are also suggested to be effective across cultural groups as, regardless of cultural background, they help problem gamblers identify and address their own influences and beliefs about gambling. ${ }^{23}$

Remote and self-help treatment options are effective, resource-efficient, anonymous, convenient, and help to reduce barriers and enhance access to treatment for those who may be unlikely or unable to use faceto-face treatment options. ${ }^{18,46-48,55}$ These interventions may be particularly effective treatment options for women, who may otherwise face barriers to treatment. ${ }^{47,50,53,55}$ Internet and workbook-based CBT may be a particularly strong option for treating gambling problems. ${ }^{17-19}$ Across remote treatment modalities, research suggests that some engagement with a clinician (in-person or via web, mobile, or telephone) may improve outcomes. ${ }^{46,50,56}$

High levels of treatment dropout also have a large impact on the outcomes of problem gambling treatment and related research. ${ }^{17,} 28$ Motivational interventions ${ }^{45}$ and interventions that engage a concerned significant other ${ }^{63}$ may help to decrease dropout rates among problem gambling treatment seekers. Several factors related to demographics, ${ }^{72}$ game preference, ${ }^{20}$ co-occurring issues, ${ }^{72,94}$ and treatment timepoints ${ }^{95}$, and treatment satisfaction ${ }^{96}$ are proposed to predict dropout. Researchers suggest that treatment providers explore which interventions can be used to address dropout at key timepoints and among key risk groups. ${ }^{72}$ Researchers also suggest that building strong therapeutic relationships at the outset of treatment may mitigate some risk of dropout. ${ }^{16}$

Overall, the evidence would suggest that a treatment strategy combining CBT with helplines, motivational interventions, and remote treatment options, has the potential to reduce barriers, enhance treatment uptake and completion, and address problematic gambling thoughts and behaviours for many problem gamblers. However, while CBT and the other strategies mentioned do have the potential to effectively treat patients with co-occurring disorders; ${ }^{32-34}$ patients with more complex diagnoses and needs may require additional forms of treatment. The literature sourced suggests that some patients may benefit from problem gambling treatment that specifically addresses sources of anxiety and depression, ${ }^{52,90,91,97}$ and patients with particularly complex needs may benefit from residential treatment options. ${ }^{67}$ Also, considering that gambling harms typically extend beyond the individual gambler, ${ }^{62}$ it may be useful to offer treatment options for concerned significant others. Research shows that engaging CSOs in treatment can be beneficial for both the CSO and the person experiencing gambling problems. ${ }^{62-65}$

Across treatment modalities, the literature identifies factors that influence treatment outcomes among a few key populations. In terms of BAME communities, researchers recommend that treatment providers should be sensitive to the differences in social and cultural backgrounds of their clients. ${ }^{23}$ Specifically, treatment providers supporting Asian problem gamblers must remember that gambling is a common pastime in this population, and should take care to address shame and fear of stigma. ${ }^{23}$ For Black and Latino/Hispanic populations, treatment providers should consider their social and environmental circumstances, since these populations are more likely to have low socioeconomic status. ${ }^{23}$ Studies on women and older adults are lacking, ${ }^{30}$ but researchers suggests that women may respond best to treatment approaches that allow for relationship building. ${ }^{30} \mathrm{~A}$ recent study suggests best practices for treatment of older adults include: 
, Person-centred and family-focused care.

, Ongoing screening and assessment.

, Secondary prevention and early intervention.

, Tertiary prevention and specialised treatment.

, Ongoing support and recovery resources. ${ }^{98}$

Across populations, the literature suggests that gambling treatment should be tailored to meet individual needs. ${ }^{99}$

\section{Limitations}

The first limitation of the current study is the lack of availability of recent research. There is a need for more robust, long-term research on many of the treatment modalities included in this review. Particularly in the areas of brain stimulation and pharmacological treatments, research using consistent treatment protocols would be useful to determine efficacy. More research is also needed regarding problem gambling treatment for women, BAME communities, gamblers with co-occurring disorders, and older and younger adults, as these groups are underrepresented in the current body of literature. Across many studies included, increased specificity regarding outcome measures (e.g., clearly defining what is meant how "decreased gambling frequency" is observed/measured) would help to clarify the nature of the impact of specific modalities on problematic gambling thoughts and behaviours.

A second limitation of this review is that, due to the time restrictions of a rapid review, robust assessments of risk of bias and quality of evidence were not conducted. As a result, the quality of studies included varies. A third limitation is that, due to availability of research, most of the included studies were carried out in jurisdictions outside of GB. Though many of the findings may be transferable to a GB context, it will be important to carry out context-specific evaluations of any updates to Great Britain's gambling treatment strategy.

Finally, it is important to acknowledge that research outside of a gambling-specific context calls into question the superiority of CBT, compared to other forms of psychotherapy. Research of this nature suggests that CBT may be the most accepted treatment standard because (1) it is the most researched, (2) it has the first and strongest evidence-based framework for results to be evaluated against, and (3) it is often used as the reference treatment in comparison studies. ${ }^{100} \mathrm{It}$ is possible that the impact of other treatment modalities on gambling problems is more difficult to measure, and thus they are not as consistently positively represented in the literature. 


\section{Conclusion}

Despite the limitations discussed, there is reasonable evidence to suggest that cognitive behavioural therapies may be the most effective treatment for problem gambling. Given that low treatment uptake and high treatment dropout are prevalent, the evidence also supports the use of modalities that increase treatment engagement, including motivational interventions, helplines, and remote and self-help interventions. Other treatment modalities reviewed demonstrate some promising evidence regarding their potential for treating gambling problems, but more research is needed to truly determine their effectiveness. More long-term, robust research is needed across treatment modalities. Future research should seek to understand which problem gambling treatment modalities are most effective for understudied subpopulations. 


\section{Appendix A:}

Glossary of Key Terms

Abstinence goal: Abstaining involves completely avoiding the problem behaviour (e.g., completely stopping all gambling behaviour). While abstinence has historically been viewed as the only way to resolve an addiction, it is very difficult for individuals struggling with addiction to achieve total abstinence. ${ }^{101}$

Addiction Severity Index (ASI): The ASI is a semi-structured interview designed to address seven potential problem areas in patients presenting with addiction problems. These seven areas include: medical status, employment and support, drug use, alcohol use, legal status, family/social status, and psychiatric status. ${ }^{102}$

Addiction Severity Index - Gambling (ASI-G): The ASI-G is a subscale of the original ASI that assesses the severity of gambling problems in a variety of populations. ${ }^{103}$

BAME: This term is used in the UK to refer to Black, Asian, and Minority Ethnic communities. ${ }^{104}$

Barriers to Treatment for Problem Gambling (BTPG): This questionnaire assesses possible barriers to gambling treatment. Subscales within this questionnaire include treatment availability, stigma, cost, uncertainty about treatment, and avoidance of gambling problems. ${ }^{105}$

Behavioural Couples Therapy (BCT): BCT is a form of behaviour therapy that incorporates both the individual and their partner in the treatment process. The focus of the treatment is on relieving stress, improving communication, managing feelings, changing behaviour, solving problems, promoting acceptance, and shifting perceptions. ${ }^{106,107}$

Brief Intervention (BI): In a gambling context, a brief intervention is an independent, short, nonconfrontational interaction about an issue related to gambling. The purpose is to help the individual think about their behaviour and make a connection between their behaviour and any associated risks and harms. ${ }^{108}$ 
Canadian Problem Gambling Index (CPGI): The CPGI is a 31-item measure used for screening purposes to determine whether a person in the general population may have a gambling problem. The CPGI asks questions about an individual's gambling habits from four categories: an individual's involvement in gambling, problem gambling behaviour, the consequences they (or others) experience as a result of their problem gambling, and other factors that often co-occur with gambling harm/problem gambling behaviour. $^{109}$

Cognitive Behavioural Therapy (CBT): This type of therapy is based on the premise that behaviour is influenced by the way an individual thinks and feels. The therapy focuses on problem solving with the goal of changing individuals' thought patterns and responses to difficult situations. A CBT approach can be applied to a wide range of mental health issues and conditions. ${ }^{110}$

Cognitive Remediation Therapy (CRT): This therapy aims to help individuals become aware of any problems with their cognitive abilities and improve upon them. Cognitive abilities may include problems with attention, working memory, planning, cognitive flexibility, and executive functioning. By routinely practicing strategies to address specific cognitive deficits, CRT aims to overcome and improve cognitive difficulties. ${ }^{111}$

Cognitive Restructuring (CR): CR therapy focuses on identifying and challenging unhelpful thoughts (referred to as cognitive distortions) and finding alternative thoughts that are more moderate and objective. CR is used in a number of therapies including CBT. ${ }^{112}$

Community Reinforcement and Family Training (CRAFT): This therapy teaches family and friends effective strategies for helping their loved ones change and feel better about themselves. CRAFT works to change the individual's behaviour through helping friends and family adopt more empathetic behaviours towards them. ${ }^{113}$

Comorbid disorders: Comorbidity describes two or more disorders or illnesses occurring in the same person. Disorders or illnesses that occur comorbidly can worsen the course or impact of each other. ${ }^{114}$

Congruence Couples Therapy (CCT): CCT was developed to provide a comprehensive couples treatment model that addresses the contribution of marital issues in problem gambling, in addition to individual cognitive behavioural factors. ${ }^{115,116}$

Conscientiousness: Conscientiousness is a personality trait that reflects the tendency to be responsible, organised, and hard-working. Specifically, conscientious individuals are goal-directed, adhere to norms and rules, and can control their impulses. Conscientiousness is considered one of the Big 5 personality traits. ${ }^{117}$

Cue Exposure Therapy (CET): This therapy exposes individuals repeatedly to addiction-related cues (e.g., the sight of poker chips) with the goal of reducing their reactions to the cues. The end goal is often that individuals no longer have any reactions to their old cues. ${ }^{118}$ 
Dopamine Antagonists (Anti-Dopaminergic Medications): Dopamine antagonists are a class of drugs that effectively blocks one or more dopamine receptors. Blocking dopamine receptors may help to interrupt the reward systems that reinforce gambling problems. Antipsychotic medications (e.g., Haloperidol) tend to be dopamine antagonists. ${ }^{119}$

DSM-5: The DSM-5 is the fifth edition of the Diagnostic and Statistical Manual (DSM) of Mental Disorders, produced by the American Psychiatric Association (APA). It is the diagnostic manual typically used by North American clinicians and researchers to diagnose and classify mental disorders, including gambling disorder. Since first being published in 1952, the DSM has undergone several revisions to take into account progress in medical and scientific knowledge, and advancements in the understanding of mental illness. ${ }^{120}$

DSM-IV: The DSM-IV is the fourth edition of the Diagnostic and Statistical Manual (DSM) of Mental Disorders, produced by the American Psychiatric Association (APA). It has been revised and updated to the DSM-IV-TR and then the DSM-5. ${ }^{121}$

DSM-IV-TR: The DSM-IV-TR is a revised and updated version DSM-IV (see above). This version has since been revised and updated to the DSM-5 (see above). ${ }^{122}$

Emotional Regulation: Emotional regulation describes the ability to control one's emotions through use of either positive or negative coping strategies. ${ }^{123}$

Exposure Therapy (ET): This therapy is a form of treatment which involves gradually increasing the level of exposure to a cue, which allows an individual to gain control over their reactions to the cue. ${ }^{124}$

Extraversion: This personality trait refers to a state where someone "recharges" or draws energy from being with other people. Extroverts tend to be outgoing, energetic, and talkative people, who search for novel experiences and social connections that allow them to interact with others as much as possible. Extroversion is considered one of the Big 5 personality traits. ${ }^{125}$

Gambler's Anonymous (GA): GA is a twelve-step program with the goal of helping participants to abstain from gambling. Anyone can join GA, and its structure is a fellowship that focuses on peer support. ${ }^{126}$

Gambling Attitudes Scale (GAS): The GAS is a 59-item measure of attitudes towards gambling in general, and attitudes toward specific forms of gambling including casinos, betting on horse races, and playing the lottery. The measure assess affective, cognitive, and behavioural components of these attitudes. ${ }^{127}$

Gambling and Craving Scale (GACS): The GACS is a 9-item scale that measures three aspects of gambling cravings, including: anticipation of positive affect, desire to gamble, and relief from negative affect. ${ }^{128}$

Gambling Beliefs Questionnaire (GBQ): The GBQ is a 21-item, self-report measure of gamblers' cognitive distortions or inaccurate beliefs around gambling. The GBQ is made up of two factors: luck/perseverance and illusion of control. ${ }^{129}$ 
Gambling Problems Index: This is a 20-item measure assessing gambling-related negative consequences in the past 6 months. ${ }^{130}$

Gambling Quantity and Perceived Norms Scale (GQPN): The GQPN is a six-item scale assessing money spent on gambling. ${ }^{130}$

Gambling Refusal Self-Efficacy Questionnaire (GRSEQ): The GRSEQ is a 26-item scale assessing an individual's perceived ability to refuse to gamble. ${ }^{131}$

Gambling Related Cognition Scale (GRCS): The GRCS is a 23-item scale that screens for a wide range of cognitive biases specific to gamblers. The GRCS includes five factors/subscales: interpretative control/ bias (GRCS-IB), illusion of control (GRCS-IC), predictive control (GRCS-PC), gambling-related expectancies (GRCS-GE), and a perceived inability to stop gambling (GRCS-IS). ${ }^{132}$

Gambling Symptom Assessment Scale (G-SAS): The G-SAS is a 12-item self-rated scale designed to assess gambling symptom severity and change during treatment. The G-SAS is not designed to be a diagnostic or screening instrument. ${ }^{133}$

Gambling Urge Scale (GUS): The GUS is a six-item self-rated questionnaire that measures the extent of gambling urges based on the participant's self-reported thoughts and feelings at the time of completing the questionnaire. ${ }^{134}$

Glutamatergic Agents (or drugs): Glutamate is the principal excitatory neurotransmitter in the nervous system. Glutamatergic agents modulate (by blocking or exciting) these neurotransmitters, which can help to interrupt the physiological reward systems that reinforce gambling problems. ${ }^{135}$

Integrative Couple Treatment for Pathological Gambling (ICT-PG): ICT-PG is a therapy in which the treatment for pathological gambling focuses on working with the couple from the first meeting. This treatment aims to help couples work together to reduce or stop a partner's stop gambling behaviour, while also reducing psychological distress experienced by both partners. Goals of ICT-PG include improving relationship satisfaction and mutual support, and enhancing skills for communication, conflict resolution, and mutual reinforcement. ${ }^{136}$

Internet-Based CBT (I-CBT): In general, an I-CBT intervention will consist of online modules rooted in CBT protocol, including behavioural activation, cognitive restructuring, problem-solving, and self-monitoring. Usually, the modules are designed to be administered on a weekly basis. ${ }^{137}$

Left Dorsolateral Prefrontal Cortex (DLPFC): The DLPFC is involved in cerebral thinking and higher executive function. More specifically, this brain region plays an important role in automating cognitive processes to solve problems by applying previously learned rules. The DLPFC is thought to be involved in cognitive tasks such as long-term memory, reasoning, and comprehension. ${ }^{138}$ 
Massachusetts Gambling Screen (MAGS): The MAGS is a brief,14-item screen based on the DSM-4 pathological gambling criteria. ${ }^{139}$

Mindfulness: Mindfulness involves paying attention to what is happening in the present moment in the mind, body, and external environment, with an attitude of curiosity and kindness. Mindfulness practice typically involves a range of simple meditation practices, which aim to bring a greater awareness to thinking, feeling, and behaviour patterns, and to develop the capacity to manage these with greater skill and compassion. ${ }^{140}$

Moderation goal: Moderation goals refer to reducing problematic behaviour to a point where the behaviour is sustainable and under control. Compared to complete abstinence, moderation is often considered a more realistic treatment goal. Moderation can also be used as a first step on the way to abstinence. ${ }^{101}$

Motivational Enhancement Therapy (MET): MET is a counselling approach that uses intervention and counselling techniques designed to help to motivate individuals to change their own thoughts and behaviours. MET encourages internally motivated change and helps patients resolve their ambivalence about engaging in treatment and changing their behaviour. This modality is commonly used in combination with other forms of counselling. ${ }^{141}$

Motivational Interviewing (MI): $\mathrm{Ml}$ is a counselling approach that uses a directive, client-centred style designed to engage clients, clarify their strengths and aspirations, evoke their own motivations for change, and promote autonomy in decision making. ${ }^{142}$

National Opinion Research Centre DSM Screen for Gambling Problems (NODS): The NODS is 34-item telephone-screening tool that identifies gambling problems as defined by the DSM-5. A self-assessment version (NODS-SA) is also available. This tool helps individuals decide if they should change their gambling behaviour or seek help for their gambling. ${ }^{143}$

Neuroticism: Neuroticism is typically defined as a tendency toward anxiety, depression, self-doubt, and other negative feelings. People with neurotic dispositions are more prone to mood disorders, loneliness, self-consciousness, and hypochondria. Neuroticism is considered one of the Big 5 personality traits. ${ }^{144}$

Opioid antagonists: Opioid antagonists are a receptor antagonist that acts on one or more of the opioid receptors. Naloxone and naltrexone are commonly used opioid antagonist drugs, which prevent the body from responding to opioids and endorphins. Blocking the body's response to opioids and endorphins may help to interrupt the physiological reward systems that reinforce gambling problems. ${ }^{145}$

Pathological Gambling Diagnostic Interview (PGDI): The PGDI is a 50-item structured interview used to evaluate gambling disorder based on the DSM-5 criteria. ${ }^{146}$

Personalized Normative Feedback (PNF): PNF aims to correct misperceptions by providing information about personal problems and patterns, compared with norms in similar-aged peer groups. PNF is intended to raise motivation for behaviour change. ${ }^{147}$ 
Placebo: Placebos are "fake" treatments, such as sugar pills in pharmacological treatment studies. Placebos are often used in studies involving a control group to provide a point of comparison that may help to determine the effectiveness of treatments. It is widely recognised that placebos themselves can result in an improvement in a patient's condition - this is often referred to as the "placebo effect". ${ }^{148}$

Problem Gambling Severity Index (PGSI): The Problem Gambling Severity Index is a nine-item tool designed to identify problem gambling, moderate risk gambling, and low risk gambling. A score of eight or more represents problem gambling, scores between three and seven represent moderate risk gambling, and a score of one or two represents low risk gambling. ${ }^{149}$

Psychodynamic therapy: Psychodynamic therapy is an in-depth form of talk therapy based on the theories and principles of psychoanalysis. Though it is similar in many ways to psychoanalytic therapy, psychodynamic therapy is less focused on the patient-therapist relationship, because it is equally focused on the patient's relationship with his or her external world. ${ }^{150}$

Psychoeducation interventions (psychoeducation): Delivered individually or in groups, psychotherapy interventions encompass a broad range of activities that combine education and other traditional counselling activities. Generally, this modality includes information about treatments, symptoms, resources and services, and problem-solving strategies. ${ }^{151}$

Psychotherapy: Psychotherapy is a type of therapy used to treat emotional problems and mental health conditions. It involves talking to a trained therapist, either one-on-one or in a group setting, but may also use other methods (e.g., art, music, drama, and movement). Psychotherapy encourages individuals to look deeper into their problems and worries, and deal with troublesome habits. ${ }^{152}$

Randomised Control Trial (RCT): An RCT is a study where people are randomly allocated to receive (or not receive) a particular intervention (this could be two different treatments or one treatment and a placebo). This study design is particularly useful at showing causation and determining whether a treatment is effective. ${ }^{153}$

Residential treatment (also called inpatient treatment or "rehab"): This type of treatment takes place within a controlled environment (usually a facility or resort) and provides the opportunity for individuals to get away from the distractions and triggers commonly found in everyday life. It allows individuals to recuperate and focus on getting physically and mentally better. ${ }^{154}$

Selective Serotonin Reuptake Inhibitor (SSRI): SSRIs work by increasing serotonin levels in the brain. Serotonin is a neurotransmitter (a messenger chemical that carries signals between nerve cells in the brain), that influences one's mood, emotion, and sleep. After carrying a message, serotonin is usually reabsorbed by the nerve cells (known as "reuptake"). SSRls work by blocking ("inhibiting") reuptake, meaning more serotonin is available to pass further messages between nearby nerve cells. ${ }^{155}$

Self-Help CBT (SHCBT): SHCBTs are psychological therapies that an individual can do on their own time to help with problems like stress, anxiety, depression, and problematic behaviours. ${ }^{18}$ 
Sensation seeking: Sensation seeking is a personality trait that involves the motivation to seek out novel experiences varying in levels of intensity and stimulation. This trait may also include the willingness to take physical, social, legal, and financial risks for the sake of such experiences. ${ }^{156}$

Sham Treatment: see "Placebo."

South Oaks Gambling Screen (SOGS): The SOGS is a 20-item questionnaire to measure problem gambling. The SOGS can be self-administered or administered by non-professional or professional interviewers. A revised and more recent version of SOGS is available (SOGS-R), as is a revised adolescent version (SOGS-RA). ${ }^{157}$

Stages of Change: Based on the Transtheoretical Model, the stages of change describe six stages an individual can move through when trying to successfully stop or change an addictive behaviour. These include precontemplation, contemplation, preparation, action, maintenance, and termination stages. ${ }^{22}$

Structured Clinical Interview for Pathological Gambling (SCI-PG): The SCI-PG is an 11-question clinicianadministered interview to screen for pathological gambling based on the DSM-IV. ${ }^{158}$

Theta Burst Stimulation (TBS): TBS is a form of non-invasive brain stimulation similar to Transcranial Magnetic Stimulation (TMS). There are two main types of TBS, intermittent TBS (iTBS), which increases brain activity in a specific region and continuous TBS (cTBS), which can decrease brain activity in a specific region. ${ }^{159}$

Timeline Follow Back (TLFB): TLFB is a method for assessing problematic behaviour. Using a calendar, a person recalls and documents a timeline of their recent problematic behaviour (e.g. when and how long they gambled). Several memory aids can be used to help with recall. There is a gambling specific version called the G-TLFB. ${ }^{160}$

Transcranial Direct Current Stimulation (tDCS): This technique alters the activity of brain cells in specific areas of the brain. In tDCS an electrical current is applied directly to the head, above the anterior temporal lobes of the brain. ${ }^{161}$

Transcranial Magnetic Stimulation (TMS): This treatment involves a person holding a device on their scalp that then delivers a magnetic pulse through the skin with the goal of activating particular areas in the brain. The device is portable and can be used at home or wherever is convenient. The number of pulses can be changed from a single pulse (sTMS) to repeated pulses (rTMS). The strength and frequency of pulses, and length of treatment can be tailored for each individual. ${ }^{162}$

Treatment Modalities: Treatment modalities refer to the different types (or modes) of treatment (e.g., CBT, motivational interviewing, pharmacological treatment, etc.). ${ }^{163}$

Tutorial Workbook (TW): TWs are a written or online self-help manual with tutorials tailored specifically to the workbook's objectives and goals. ${ }^{55}$ 
Victoria Gambling Screen (VGS): The VGS is a 21-item instrument used to measure problem gambling, with a focus on three aspects: enjoyment of gambling, harm to others, and harm to self. ${ }^{164}$

World Health Organization World Mental Health Composite International Diagnostic Interview (WHM-CIDI): The WHIM-CIDI is a comprehensive, structured interview designed to be used by trained lay interviewers for the assessment of mental disorders according to the definitions and criteria of International Statistical Classification of Diseases and Related Health Problems-10 (ICD-10) and DSM-IV. ${ }^{165}$

Yale-Brown Obsessive Compulsive Scale Modified for Pathological Gambling (PG-YBOCS): The PG-YBOCS is a 10 -item clinician-administered questionnaire developed to measure the severity and change in severity of pathological gambling symptoms. ${ }^{166}$ 


\section{Appendix B: Search Strings}

Initial searches were performed October 16, 2019.

Supplementary searches were performed November 14, 2019.

\section{INITIAL SEARCHES}

1. PubMed search: All articles on gambling under the topic "Treatment Outcomes", 2014-2019 (99 results)

( ( ( "Treatment Outcome" [MeSH Terms])

AND gambl*[Title/Abstract])

AND ("2014"[Date - Publication] : "3000"[Date - Publication])

NOT "standard gamble"[Title/Abstract]) NOT Iowa[Title/Abstract])

2. PubMed search: systematic reviews and meta-analyses on gambling under the topic Treatment Outcomes", 2009-2019 (13 results)

( ("Treatment Outcome"[MeSH Terms])

AND gambl*[Title/Abstract])

AND ("2009"[Date - Publication] : "3000"[Date - Publication])

AND ("systematic review" OR "meta-analysis"[Publication Type])

3. GREO Evidence Centre Search: Topic "Interventions", 2014-2019, with document types restricted to Research Snapshots (109 results) and grey literature reports (14 results)

https://www.greo.ca/Modules/EvidenceCentre/Search. aspx? \&page $=1$ \&rows $=10 \&$ cffactor $=\% 22$ Resources $\% 20-\% 20$

Interventions\%22\&resourceType=research\%20snapshots|grey\%20

literature\&glgroup $=$ Reports\&DatePublishedFrom $=2014 \&$ DatePublishedTo=2019 


\section{SUPPLEMENTARY SEARCHES: HELPLINES AND RESIDENTIAL TREATMENT}

4. PubMed search: All articles under the topic "Gambling" and a residential treatment topic, 2014-2019 (9 results)

( (gambling [MeSH Terms]))

AND ((inpatients OR hospitalization OR institutionalization [MeSH Terms]))

AND ("2014"[Date - Publication] : "3000"[Date - Publication])

5. PsycINFO search: All articles under a gambling topic and the "Residential care institutions" topic, 2014-2019 (3 results)

Index Terms: \{Gambling\} OR \{Gambling Disorder\} AND Index Terms:

\{Residential Care Institutions\} AND Year: 2014 To 2019

6. PubMed search: All articles under the topic "Gambling" and the topic "Hotlines" (8 results)

( (gambling AND hotlines[MeSH Terms]))

AND ("2014"[Date - Publication] : "3000"[Date - Publication])

7. PsycINFO search: All articles under a gambling topic and the "Hot Line Services" topic, 2014-2019 (2 results)

Index Terms: \{Gambling\} OR \{Gambling Disorder\} AND Index Terms:

\{Hot Line Services\} AND Year: 2014 To 2019 


\section{Appendix C:}

\section{Summary of Study Details}

\section{Summary of Study Details}

\begin{tabular}{l} 
Study \\
Boudreault et al., \\
2018 \\
Boughton et al., \\
2016 \\
Boughton et al., \\
2017 \\
Buchner et al., \\
2015 \\
Bucker et al., 2018 \\
\hline $\begin{array}{l}\text { Campos et al., } \\
2015\end{array}$ \\
\hline
\end{tabular}

Casey et al., 2017

Challet-Bouju et al., 2017

Chamberlain \&
Grant, 2019

\section{Chebli et al., 2016}

Choi et al., 2016

Danielsson et al., 2014

de Brito et al., 2017

Canada

Canada

Canada

Germany

Germany

Australia

France

Australia

South Korea

Sweden

Brazil

Country

United States

United Kingdom; United States
Mode(s) of treatment

MI, Self-help

GT, Mindfulness

Residential

treatment

Deprexis

Self-help

CBT

\section{Cognitive} remediation

Pharmacotherapy

Review

\section{Study design}

Experimental: RCT

Observational:

Cohort

\section{Observational:}

Cross-sectional

Evaluation

Experimental: RCT

Experimental: RCT

87

Experimental: RCT

Review

Review

Observational:

Chart Review

Pharmacotherapy,

Psychotherapy

Help-lines, Online interventions

Review

Drugs, CBT

62

55

Experimental: RCT 38

\section{Sample size}

25, 11 completed

140

50 studies

approx. 90 studies (not clearly defined in methods)

16 studies

758

74 studies
SOGS, PG-YBOCS

NODS, SCl-PG, SOGS, G-SAS

G-SAS, SOGS, GUS, GRSEQ

G-SAS

Measure of problem gambling severity

PGSI, PGDI, DSM-5

DSM-IV, CPGI

DSM-IV, CPGI

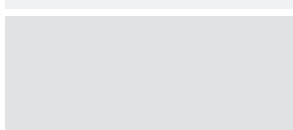

G-SAS, TLFB interviews, GBQ 


\section{Summary of Study Details continued}

\begin{tabular}{|c|c|c|c|c|c|}
\hline Study & Country & $\begin{array}{l}\text { Mode(s) of } \\
\text { treatment }\end{array}$ & Study design & Sample size & $\begin{array}{l}\text { Measure of problem } \\
\text { gambling severity }\end{array}$ \\
\hline $\begin{array}{l}\text { Deepmala et al., } \\
2015\end{array}$ & United States & Pharmacotherapy & Review & 65 studies & \\
\hline $\begin{array}{l}\text { DiClemente et al., } \\
2017\end{array}$ & United States & MI & Review & 144 studies & \\
\hline $\begin{array}{l}\text { Gainsbury \& } \\
\text { Blaszczynski, } 2011\end{array}$ & Australia & $\begin{array}{l}\text { CBT, MI, Online } \\
\text { interventions }\end{array}$ & Review & 9 & NODS \\
\hline $\begin{array}{l}\text { Garcia-Caballero et } \\
\text { al., } 2018\end{array}$ & Spain & CBT, GT, MI & $\begin{array}{l}\text { Observational: } \\
\text { Cohort }\end{array}$ & 18 & NODS \\
\hline Gay et al. 2017 & France & Brain stimulation & $\begin{array}{l}\text { Experimental: } \\
\text { Non-RCT }\end{array}$ & 22 & PG-YBOCS \\
\hline $\begin{array}{l}\text { Gomes \& Pascual- } \\
\text { Leone, } 2015\end{array}$ & Canada & $\begin{array}{l}\text { GT, Residential } \\
\text { treatment }\end{array}$ & Descriptive: Survey & 50,24 completed & PGSI \\
\hline $\begin{array}{l}\text { Gooding \& Tarrier, } \\
2009\end{array}$ & United Kingdom & CBT & Review & 25 studies & \\
\hline Gori et al., 2016 & Italy & $\begin{array}{l}\text { Residential } \\
\text { treatment }\end{array}$ & $\begin{array}{l}\text { Observational: } \\
\text { Cross-sectional }\end{array}$ & 204 & SOGS \\
\hline Goslar et al., 2019 & Austria, Germany & Pharmacotherapy & Review & 34 studies & $\begin{array}{l}\text { PG-YBOCS, } \\
\text { G-SAS, SOGS }\end{array}$ \\
\hline $\begin{array}{l}\text { Grant \& } \\
\text { Chamberlain, } 2015\end{array}$ & $\begin{array}{l}\text { United States; } \\
\text { United Kingdom }\end{array}$ & All types & Review & $\begin{array}{l}\text { approx. } 75 \text { studies } \\
\text { (not clearly defined } \\
\text { in methods) }\end{array}$ & \\
\hline Grant et al., 2014 & United States & Pharmacotherapy & $\begin{array}{l}\text { Experimental: } \\
\text { Non-RCT }\end{array}$ & 28 & PG-YBOCS \\
\hline Guo et al., 2014 & Singapore & CBT & Longitudinal & 80 & G-SAS \\
\hline $\begin{array}{l}\text { Harris \& } \\
\text { Mazmanian, } 2016\end{array}$ & Canada & CBT, GT & Experimental: RCT & 32 & DSM-IV-TR \\
\hline $\begin{array}{l}\text { Hedman et al., } \\
2012\end{array}$ & Sweden & Internet-based CBT & Review & 108 studies & \\
\hline $\begin{array}{l}\text { Hodgins, et al., } \\
2019\end{array}$ & Canada & $\mathrm{BI}$ & Experimental: RCT & 181 & NODS, PGSI \\
\hline
\end{tabular}


Summary of Study Details continued

\begin{tabular}{|c|c|c|c|c|c|}
\hline Study & Country & $\begin{array}{l}\text { Mode(s) of } \\
\text { treatment }\end{array}$ & Study design & Sample size & $\begin{array}{l}\text { Measure of problem } \\
\text { gambling severity }\end{array}$ \\
\hline $\begin{array}{l}\text { Jimenez-Murcia } \\
\text { et al., } 2015\end{array}$ & Spain & CBT & $\begin{array}{l}\text { Observational: } \\
\text { Cohort }\end{array}$ & 440 & DSM-IV, SCID-I \\
\hline $\begin{array}{l}\text { Jimenez-Murcia } \\
\text { et al., } 2017\end{array}$ & Spain & CBT & $\begin{array}{l}\text { Experimental: } \\
\text { Non-RCT }\end{array}$ & 675 & SOGS \\
\hline Khanbhai, 2017 & Australia & CBT & $\begin{array}{l}\text { Descriptive: } \\
\text { Survey/Interview } \\
\text { or Focus Group/ } \\
\text { Observational: } \\
\text { Cross-sectional }\end{array}$ & 410 & PGSI \\
\hline $\begin{array}{l}\text { Khayyat-Abuaita } \\
\text { et al., } 2015\end{array}$ & $\begin{array}{l}\text { United States; } \\
\text { Canada }\end{array}$ & Help-lines & $\begin{array}{l}\text { Descriptive: } \\
\text { Survey/Interview }\end{array}$ & 143 & NODS, BTPG \\
\hline Kim et al., 2016 & $\begin{array}{l}\text { Canada, New } \\
\text { Zealand }\end{array}$ & Help-lines & $\begin{array}{l}\text { Experimental: Non- } \\
\text { RCT (secondary } \\
\text { analysis) }\end{array}$ & 150 & PGSI \\
\hline $\begin{array}{l}\text { Kovanen et al., } \\
2016\end{array}$ & Finland & $\begin{array}{l}\text { Pharmaco- } \\
\text { therapy, } \\
\text { psychosocial } \\
\text { support }\end{array}$ & Experimental: RCT & 101 & $\begin{array}{l}\text { SOGS, DSM-5, } \\
\text { TLFB-G, PG- } \\
\text { YBOCS }\end{array}$ \\
\hline $\begin{array}{l}\text { Leavens et al., } \\
2014\end{array}$ & United States & $\begin{array}{l}\text { Residential } \\
\text { treatment }\end{array}$ & Descriptive: Survey & 684 & SOGS, ASI \\
\hline $\begin{array}{l}\text { Lee \& Awosoga, } \\
2015\end{array}$ & Canada & $\begin{array}{l}\text { Other talk therapy, } \\
\text { Congruence } \\
\text { Couple Therapy }\end{array}$ & Experimental: RCT & 15 couples & G-SAS \\
\hline $\begin{array}{l}\text { Linardatou et al., } \\
2014\end{array}$ & Greece & $\begin{array}{l}\text { GT, Stress } \\
\text { management } \\
\text { therapy, GA }\end{array}$ & Experimental: RCT & 45 & DSM-IV \\
\hline Linnet et al., 2017 & Denmark & CBT & $\begin{array}{l}\text { Observational: } \\
\text { Cohort }\end{array}$ & 61 & DSM-IV, SOGS \\
\hline Maniaci et al., 2017 & Italy & Other talk therapy & Experimental: RCT & 272 & SOGS \\
\hline $\begin{array}{l}\text { Manning et al., } \\
2014\end{array}$ & Singapore & CBT, GT & $\begin{array}{l}\text { Observational: } \\
\text { Cross-sectional }\end{array}$ & 389 & G-SAS \\
\hline $\begin{array}{l}\text { Matheson et al., } \\
2018\end{array}$ & Canada & All treatment types & Review & 247 criteria & \\
\hline
\end{tabular}




\section{Summary of Study Details continued}

\begin{tabular}{|c|c|c|c|c|c|}
\hline Study & Country & $\begin{array}{l}\text { Mode(s) of } \\
\text { treatment }\end{array}$ & Study design & Sample size & $\begin{array}{l}\text { Measure of problem } \\
\text { gambling severity }\end{array}$ \\
\hline $\begin{array}{l}\text { Matheson et al., } \\
\text { 2019. The use of } \\
\text { self-management... }\end{array}$ & Canada & Self-help & Review & 31 & \\
\hline $\begin{array}{l}\text { Matheson et al., } \\
2019 \text { Women } \\
\text { creating... }\end{array}$ & Canada & Arts-based support & $\begin{array}{l}\text { Pilot program } \\
\text { evaluation }\end{array}$ & 12 & \\
\hline $\begin{array}{l}\text { Mclntosh et al., } \\
2016\end{array}$ & Australia & CBT, Mindfulness & Experimental: RCT & 77 & SOGS, DSM-5 \\
\hline $\begin{array}{l}\text { Merkouris et al., } \\
2016\end{array}$ & Australia & $\begin{array}{l}\text { CBT, BI, Exposure } \\
\text { therapy, GT, } \\
\text { Help-lines, } \\
\text { MI, Mindfulness, } \\
\text { Other talk therapy, } \\
\text { Residential } \\
\text { treatment, } \\
\text { Self-help }\end{array}$ & Review & 50 & \\
\hline $\begin{array}{l}\text { Mestre-Bach et al., } \\
2016\end{array}$ & Spain & CBT & $\begin{array}{l}\text { Observational: } \\
\text { Cross sectional } \\
\text { study }\end{array}$ & 88 & DSM-IV-TR \\
\hline $\begin{array}{l}\text { Mestre-Bach et al., } \\
2019\end{array}$ & Spain & CBT & $\begin{array}{l}\text { Observational: } \\
\text { Longitudinal/ } \\
\text { Cohort }\end{array}$ & 398 & DSM-5, SOGS \\
\hline Monnat et al., 2014 & United States & $\begin{array}{l}\text { Individual, family } \\
\text { and group } \\
\text { counseling, } \\
\text { CBT, Self-help } \\
\text { groups, and } \\
\text { Psycho-education }\end{array}$ & Descriptive: Survey & 361 & $\begin{array}{l}\text { Author-designed } \\
\text { questionnaire }\end{array}$ \\
\hline $\begin{array}{l}\text { Mooney et al., } \\
2019\end{array}$ & United Kingdom & $\begin{array}{l}\text { Psychodynamic } \\
\text { therapy }\end{array}$ & $\begin{array}{l}\text { Observational: } \\
\text { Cross-sectional } \\
\text { (pilot) }\end{array}$ & 72 & PGSI, DSM-5 \\
\hline $\begin{array}{l}\text { Morefield et a., } \\
2014\end{array}$ & Australia & $\begin{array}{l}\text { CBT, Exposure } \\
\text { therapy, Residential } \\
\text { treatment }\end{array}$ & $\begin{array}{l}\text { Observational: } \\
\text { Cross-sectional } \\
\text { (pilot) }\end{array}$ & 53 & VGS \\
\hline
\end{tabular}




\section{Summary of Study Details continued}

\begin{tabular}{|c|c|c|c|c|c|}
\hline Study & Country & $\begin{array}{l}\text { Mode(s) of } \\
\text { treatment }\end{array}$ & Study design & Sample size & $\begin{array}{l}\text { Measure of problem } \\
\text { gambling severity }\end{array}$ \\
\hline Muller et al., 2017 & Germany & $\begin{array}{l}\text { CBT, GT, Other } \\
\text { talk therapy, } \\
\text { Ergo-therapy, } \\
\text { Sports therapy, } \\
\text { Physiotherapy, } \\
\text { Nutrition } \\
\text { Counselling, } \\
\text { Social therapy, and } \\
\text { Creative therapies }\end{array}$ & $\begin{array}{l}\text { Observational: } \\
\text { cross-sectional }\end{array}$ & 270 & SOGS-R, SCI-PG \\
\hline Naish et al., 2018 & Canada & Brain stimulation & Review & 24 & \\
\hline $\begin{array}{l}\text { Nayoski \& Hodgins, } \\
2016\end{array}$ & Canada & CRAFT & Experimental: RCT & 31 & $\begin{array}{l}\text { DSM-IV-TR } \\
\text { (as reported by } \\
\text { CSO), TLFB-G }\end{array}$ \\
\hline Nehlin et al., 2016 & Sweden & $\mathrm{BI}$ & $\begin{array}{l}\text { Observational: } \\
\text { Cross-sectional } \\
\text { (pilot) }\end{array}$ & 34,19 completed & NODS-PERC \\
\hline $\begin{array}{l}\text { Neighbors et al., } \\
2015\end{array}$ & United States & $\begin{array}{l}\text { BI, Personalized } \\
\text { normative } \\
\text { feedback, } \\
\text { Attention control } \\
\text { feedback }\end{array}$ & Experimental: RCT & 252 & SOGS, GQPN, GPI \\
\hline Nilsson et al, 2017 & Sweden & CBT, BCT & Experimental: RCT & 36 & $\begin{array}{l}\text { NODS, DSM-IV, } \\
\text { TLFB-G }\end{array}$ \\
\hline Oei, 2017 & $\begin{array}{l}\text { Australia; China; } \\
\text { Singapore }\end{array}$ & CBT, Self-help & Experimental: RCT & 55 & $\begin{array}{l}\text { CPGI, GRCS, GUS, } \\
\text { GRSEQ }\end{array}$ \\
\hline $\begin{array}{l}\text { Parker \& } \\
\text { Bauermann, } 2015\end{array}$ & Canada & CBT & Review & 40 & \\
\hline Petry et al., 2016 & United States & $\begin{array}{l}\mathrm{BI}, \mathrm{CBT} \text {, } \\
\text { Motivational } \\
\text { enhancement } \\
\text { therapy }\end{array}$ & Experimental: RCT & 217 & DSM-5, TLFB \\
\hline Petry, et al., 2017 & United States & $\mathrm{BI}, \mathrm{CBT}, \mathrm{MI}$ & Review & 21 studies & \\
\hline Pfund et al., 2018 & United States & MI, Self-help & Experimental: RCT & 69 & DSM-IV \\
\hline Pfund et al., 2017 & United States & CBT & $\begin{array}{l}\text { Secondary data } \\
\text { analysis }\end{array}$ & 334 & DSM-V \\
\hline
\end{tabular}




\section{Summary of Study Details continued}

\begin{tabular}{|c|c|c|c|c|c|}
\hline Study & Country & $\begin{array}{l}\text { Mode(s) of } \\
\text { treatment }\end{array}$ & Study design & Sample size & $\begin{array}{l}\text { Measure of problem } \\
\text { gambling severity }\end{array}$ \\
\hline $\begin{array}{l}\text { Ramos-Grille et al., } \\
2015\end{array}$ & Spain & CBT & $\begin{array}{l}\text { Experimental: } \\
\text { Non-RCT/ } \\
\text { Naturalistic } \\
\text { follow-up }\end{array}$ & 132 & NODS \\
\hline Ranta et al., 2019 & New Zealand & Help-lines & $\begin{array}{l}\text { Observational: } \\
\text { Cohort }\end{array}$ & 131 & PGSI \\
\hline Richard et al., 2017 & United States & CBT, MI & Review & $\begin{array}{l}\text { approx. } 70 \text { studies } \\
\text { (not clearly defined } \\
\text { in methods) }\end{array}$ & \\
\hline Riley, 2015 & South Australia & CBT & $\begin{array}{l}\text { Observational: } \\
\text { Cohort }\end{array}$ & 45 & VGS-HS \\
\hline Roberts et al., 2019 & United Kingdom & $\begin{array}{l}\text { Residential } \\
\text { treatment }\end{array}$ & $\begin{array}{l}\text { Secondary data } \\
\text { analysis }\end{array}$ & 658 & PGSI \\
\hline Rodda et al., 2016 & Australia & E-interventions & Review & 28 studies & \\
\hline Rogers et al., 2019 & United Kingdom & GT & $\begin{array}{l}\text { Descriptive: } \\
\text { Qualitative }\end{array}$ & 20 meetings & \\
\hline Ronzitti et al., 2015 & United Kingdom & CBT & $\begin{array}{l}\text { Observational: } \\
\text { Cross-sectional }\end{array}$ & 676 & PGSI \\
\hline Ronzitti et al., 2018 & United Kingdom & CBT & $\begin{array}{l}\text { Observational: } \\
\text { Longitudinal/ } \\
\text { Cohort; } \\
\text { Observational: } \\
\text { Cross-sectional }\end{array}$ & 524 & PGSI \\
\hline $\begin{array}{l}\text { Rossini-Dib et al., } \\
2015\end{array}$ & Brazil & $\begin{array}{l}\text { CBT, Psycho- } \\
\text { education }\end{array}$ & $\begin{array}{l}\text { Observational: } \\
\text { Cross-sectional }\end{array}$ & 113 & ASI-G, GBO \\
\hline $\begin{array}{l}\text { Sauvaget et al., } \\
2018\end{array}$ & France & Brain stimulation & $\begin{array}{l}\text { Experimental: } \\
\text { Non-RCT }\end{array}$ & 30 & $\begin{array}{l}\text { GACS, DSM-IV, } \\
\text { GRCS, GRCS-IC, } \\
\text { GRCS-PC, GRCS-IB, } \\
\text { GRCS-GE, GRCS-IS }\end{array}$ \\
\hline Schuler et al., 2016 & Canada & GA & Review & 17 articles & \\
\hline Skinner et al., 2018 & Canada & Best practices & $\begin{array}{l}\text { Evaluation } \\
\text { Design/Program } \\
\text { Evaluation/Review }\end{array}$ & 247 & \\
\hline
\end{tabular}




\section{Summary of Study Details continued}

\begin{tabular}{|c|c|c|c|c|c|}
\hline Study & Country & $\begin{array}{l}\text { Mode(s) of } \\
\text { treatment }\end{array}$ & Study design & Sample size & $\begin{array}{l}\text { Measure of problem } \\
\text { gambling severity }\end{array}$ \\
\hline $\begin{array}{l}\text { Smith et al., } \\
\text { 2015. Effects } \\
\text { of affective... }\end{array}$ & Australia & СBT & $\begin{array}{l}\text { Observational: } \\
\text { Cohort }\end{array}$ & 380 & VGS \\
\hline $\begin{array}{l}\text { Smith et al., } 2015 . \\
\text { Cognitive vs. } \\
\text { exposure... }\end{array}$ & Australia & CBT, ET & Experimental: RCT & 87 & VGS, GRCS, GUS \\
\hline Smith et al., 2018 & Australia & CBT, ET & $\begin{array}{l}\text { Experimental: RCT/ } \\
\text { Review }\end{array}$ & $\begin{array}{l}51(\mathrm{RCT}), 269 \\
\text { (clinical sample) }\end{array}$ & VGS, GRCS, GUS \\
\hline $\begin{array}{l}\text { Soberay et al., } \\
2014 \text {. Stages } \\
\text { of change... }\end{array}$ & United States & $\begin{array}{l}\text { CBT, Time-limited } \\
\text { psychodynamic } \\
\text { therapy, } \\
\text { Solution-focused } \\
\text { brief therapy }\end{array}$ & $\begin{array}{l}\text { Experimental: } \\
\text { Non-RCT }\end{array}$ & 71 & NODS \\
\hline $\begin{array}{l}\text { Soberay et al., } \\
\text { 2014. Pathological } \\
\text { gambling... }\end{array}$ & United States & $\begin{array}{l}\text { CBT, Time-limited } \\
\text { dynamic } \\
\text { psychotherapy, } \\
\text { Solution-focused } \\
\text { brief therapy }\end{array}$ & $\begin{array}{l}\text { Observational: } \\
\text { Cohort }\end{array}$ & 53 & NODS-SA \\
\hline $\begin{array}{l}\text { Spagnolo et al., } \\
2018\end{array}$ & United States; Italy & Brain stimulation & Review & 31 studies & \\
\hline Stea et al., 2015 & Canada & MI & $\begin{array}{l}\text { Secondary data } \\
\text { analysis }\end{array}$ & 314 & SOGS \\
\hline Tolchard, 2017 & $\begin{array}{l}\text { Australia; United } \\
\text { States }\end{array}$ & CBT & Review & 27 studies & \\
\hline Toneatto, 2016 & Canada & CBT, MI & Experimental: RCT & 99 & DSM-5 \\
\hline $\begin{array}{l}\text { Tremblay et al., } \\
2017\end{array}$ & Canada & ICT-PG & $\begin{array}{l}\text { Experimental: RCT } \\
\text { (pilot) }\end{array}$ & 21 couples & WHM-CIDI \\
\hline $\begin{array}{l}\text { Valdivia-Salas et al., } \\
2014\end{array}$ & Spain & Help-lines & $\begin{array}{l}\text { Secondary data } \\
\text { analysis }\end{array}$ & 454 & \\
\hline $\begin{array}{l}\text { van der Maas et al., } \\
2019\end{array}$ & Canada & $\begin{array}{l}\text { Internet-based } \\
\text { interventions }\end{array}$ & Review & 27 studies & $\begin{array}{l}\text { PGSI, GAS, SOGS, } \\
\text { SOGS-R, SOGS- } \\
\text { RA, NODS }\end{array}$ \\
\hline Ward et al., 2018 & United Kingdom & Pharmacotherapy & $\begin{array}{l}\text { Observational: } \\
\text { Chart review }\end{array}$ & 10 & \\
\hline
\end{tabular}




\section{Summary of Study Details continued}

\begin{tabular}{|c|c|c|c|c|c|}
\hline Study & Country & $\begin{array}{l}\text { Mode(s) of } \\
\text { treatment }\end{array}$ & Study design & Sample size & $\begin{array}{l}\text { Measure of problem } \\
\text { gambling severity }\end{array}$ \\
\hline $\begin{array}{l}\text { Wittekind et al., } \\
2019\end{array}$ & Germany & $\begin{array}{l}\text { Approach bias } \\
\text { modification }\end{array}$ & Experimental: RCT & 131 & SOGS \\
\hline Wong et al., 2015 & Hong Kong & CBT & Experimental: RCT & 38 & SOGS, GRCS, GUS \\
\hline $\begin{array}{l}\text { Yakovenko \& } \\
\text { Hodgins } 2016\end{array}$ & Canada & $\begin{array}{l}\text { BI, CBT, } \\
\text { Pharmacotherapy, } \\
\text { Web-based } \\
\text { treatment }\end{array}$ & Review & $\begin{array}{l}\text { approx. } 40 \text { studies } \\
\text { (not clearly defined } \\
\text { in methods) }\end{array}$ & \\
\hline $\begin{array}{l}\text { Yakovenko et al., } \\
2015\end{array}$ & Canada & $\mathrm{MI}$ & Review & $\begin{array}{l}8 \text { studies } \\
\text { (systematic review), } \\
5 \text { (meta-analysis) }\end{array}$ & \\
\hline Zack et al., 2016 & Canada & Brain stimulation & $\begin{array}{l}\text { Experimental: } \\
\text { Non-RCT }\end{array}$ & 9 & NODS, SOGS \\
\hline Zhuang et al., 2018 & Australia, China & CBT & $\begin{array}{l}\text { Experimental: } \\
\text { Non-RCT }\end{array}$ & 84 & SOGS, GUS, GRCS \\
\hline
\end{tabular}




\section{| References}

1. Haby MM, Chapman E, Clark R, Barreto J, Reveiz L, Lavis JN. What are the best methodologies for rapid reviews of the research evidence for evidence-informed decision making in health policy and practice: a rapid review. Health Research Policy and Systems. 2016;14(1):83.

2. Moher D, Liberati A, Tetzlaff J, Altman DG. Preferred reporting items for systematic reviews and meta-analyses: the PRISMA statement. PLoS Med. 2009;6(7):e1000097.

3. Grant JE, Chamberlain SR. Gambling disorder and its relationship with substance use disorders: implications for nosological revisions and treatment. The American Journal on Addictions. 2015;24(2):126-31. Plain language summary available at https://www.greo.ca/Modules/EvidenceCentre/Details/review-clinical-and-genetic-similarities-betweengambling-disorder-and-substance-use

4. Yakovenko I, Hodgins DC. Latest developments in treatment for disordered gambling: review and critical evaluation of outcome studies. Current Addiction Reports. 2016;3(3):299-306. Plain language summary available at https://www.greo. ca/Modules/EvidenceCentre/Details/review-recent-research-treatment-disordered-gambling

5. Gooding P, Tarrier N. A systematic review and meta-analysis of cognitive-behavioural interventions to reduce problem gambling: hedging our bets? Behaviour Research and Therapy. 2009;47(7):592-607.

6. McIntosh CC, Crino RD, O'Neill K. Treating problem gambling samples with cognitive behavioural therapy and mindfulness-based interventions: a clinical trial. Journal of Gambling Studies. 2016;32(4):1305-25. Plain language summary available at https://www.greo.ca/Modules/EvidenceCentre/Details/cognitive-behavioural-treatment-andmindfulness-reduce-problem-gambling-behaviour

7. Mestre-Bach G, Steward T, Granero R, Fernandez-Aranda F, Del Pino-Gutierrez A, Mallorqui-Bague N, et al. The predictive capacity of DSM-5 symptom severity and impulsivity on response to cognitive-behavioral therapy for gambling disorder: a 2-year longitudinal study. European Psychiatry. 2019;55:67-73.

8. Smith DP, Fairweather-Schmidt AK, Harvey PW, Battersby MW. How does routinely delivered cognitive-behavioural therapy for gambling disorder compare to "gold standard" clinical trial? Clinical Psychology and Psychotherapy. 2018;25(2):302-10.

9. Tolchard B. Cognitive-behavior therapy for problem gambling: a critique of current treatments and proposed new unified approach. Journal of Mental Health. 2017;26(3):283-90. Plain language summary available at https://www.greo.cal Modules/EvidenceCentre/Details/a-unified-model-for-cognitive-behavioural-therapy-in-the-treatment-of-problem-gam

10. Smith DP, Battersby MW, Harvey PW, Pols RG, Ladouceur R. Cognitive versus exposure therapy for problem gambling: randomised controlled trial. Behaviour Research and Therapy. 2015;69:100-10.

11. Petry NM, Rash CJ, Alessi SM. A randomized controlled trial of brief interventions for problem gambling in substance abuse treatment patients. Journal of Consulting and Clinical Psychology. 2016;84(10):874-86. Plain language summary available at https://www.greo.ca/Modules/EvidenceCentre/Details/brief-treatments-problem-gambling-can-be-effectivepatients-substance-use-disorders

12. Parker JDA, Bauermann TM. Outcome of psychological treatments of pathological gambling: a review and meta-analysis. Gambling Research Exchange Ontario (GREO); 2015. Available from: https://www.greo.ca/Modules/ EvidenceCentre/Details/outcome-of-psychological-treatments-of-pathological-gambling-a-review-and-meta-a-1

13. Petry NM, Ginley MK, Rash CJ. A systematic review of treatments for problem gambling. Psychology of Addictive Behaviors. 2017;31(8):951-61. Plain language summary available at https://www.greo.ca/Modules/EvidenceCentre/Details/a-review-of-psychosocial-interventions-for-problem-gambling 
14. Harris N, Mazmanian D. Cognitive behavioural group therapy for problem gamblers who gamble over the internet: a controlled study. Journal of Gambling Issues. 2016;2016(33):170-88. Plain language summary available at https:// www.greo.ca/Modules/EvidenceCentre/Details/cognitive-behavioural-therapy-is-an-effective-treatment-for-internetproblem-gam

15. Zhuang XY, Wong DFK, Ng TK, Jackson AC, Dowling NA, Lo HH. Evaluating the effectiveness of an integrated cognitive-behavioural intervention (CBI) model for male problem gamblers in Hong Kong: a matched-pair comparison design. Journal of Gambling Studies. 2018;34(3):969-85. Plain language summary available at https://www.greo.ca/ Modules/EvidenceCentre/Details/an-integrated-cbi-intervention-for-chinese-people-with-gambling-problems

16. Jimenez-Murcia S, Granero R, Fernandez-Aranda F, Arcelus J, Aymami MN, Gomez-Pena M, et al. Predictors of outcome among pathological gamblers receiving cognitive behavioral group therapy. European Addiction Research. 2015;21(4):169-78. Plain language summary available at https://www.greo.ca/Modules/EvidenceCentre/Details/usingindividual-characteristics-predict-success-cognitive-behavioural-therapy-treatment

17. Casey LM, Oei TPS, Raylu N, Horrigan K, Day J, Ireland M, et al. Internet-based delivery of cognitive behaviour therapy compared to monitoring, feedback and support for problem gambling: a randomised controlled trial. Journal of Gambling Studies. 2017;33(3):993-1010. Plain language summary available at https://www.greo.ca/Modules/ EvidenceCentre/Details/evaluating-an-internet-based-cognitive-behavioural-therapy-for-problem-gambling

18. Oei TPS, Raylu N, Lai WW. Effectiveness of a self help cognitive behavioural treatment program for problem gamblers: a randomised controlled trial. Journal of Gambling Studies. 2018;34(2):581-95. Plain language summary available at https://www.greo.ca/Modules/EvidenceCentre/Details/a-self-help-cognitive-behavioural-treatment-program-can-bebeneficial-for-problem

19. Hedman E, Ljotsson B, Lindefors N. Cognitive behavior therapy via the Internet: a systematic review of applications, clinical efficacy and cost-effectiveness. Expert Review of Pharmacoeconomics and Outcomes Research. 2012;12(6):745-64.

20. Ronzitti S, Soldini E, Smith N, Bayston A, Clerici M, Bowden-Jones H. Are treatment outcomes determined by type of gambling? A UK study. Journal of Gambling Studies. 2018;34(3):987-97. Plain language summary available at https:// www.greo.ca/Modules/EvidenceCentre/Details/gambling-treatment-completion-may-be-affected-by-participation-incertain-gamblin

21. Soberay AD, Grimsley P, Faragher JM, Barbash M, Berger B. Stages of change, clinical presentation, retention, and treatment outcomes in treatment-seeking outpatient problem gambling clients. Psychology of Addictive Behaviors. 2014;28(2):414-9.

22. Prochaska JO, DiClemente CC. Stages and processes of self-change of smoking: Toward an integrative model of change. Journal of Consulting and Clinical Psychology. 1983;51(3):390-5.

23. Richard K, Baghurst T, Faragher JM, Stotts E. Practical treatments considering the role of sociocultural factors on problem gambling. Journal of Gambling Studies. 2017;33(1):265-81. Plain language summary available at https://www.greo.ca/Modules/EvidenceCentre/Details/social-and-cultural-factors-impact-problem-gambling-variousracialethnic-groups

24. Manning V, Ng A, Koh PK, Guo S, Gomathinayagam K, Wong KE. Pathological gamblers in Singapore: treatment response at 3 months. Journal of Addiction Medicine. 2014;8(6):462-9.

25. Choi SW, Shin YC, Youn H, Lim SW, Ha J. Pharmacotherapy and group cognitive behavioral therapy enhance follow-up treatment duration in gambling disorder patients. Annals of General Psychiatry. 2016;15(20). Plain language summary available at https://www.greo.ca/Modules/EvidenceCentre/Details/pathological-gamblers-who-receive-moreintensive-treatment-stay-treatment-longer 
26. Wong DF, Chung CL, Wu J, Tang J, Lau P, Wan JP. A preliminary study of an integrated and culturally attuned cognitive behavioral group treatment for Chinese problem gamblers in Hong Kong. Journal of Gambling Studies. 2015;31(3):1015-27. Plain language summary available at https://www.greo.ca/Modules/EvidenceCentre/Details/ developing-cognitive-behavioural-therapy-treatment-chinese-problem-gamblers

27. Guo S, Manning V, Thane KK, Ng A, Abdin E, Wong KE. Predictors of treatment outcome among Asian pathological gamblers (PGs): clinical, behavioural, demographic, and treatment process factors. Journal of Gambling Studies. 2014;30(1):89-103.

28. Khanbhai Y, Smith D, Battersby M. Gender by preferred gambling activity in treatment seeking problem gamblers: a comparison of subgroup characteristics and treatment outcomes. Journal of Gambling Studies. 2017;33(1):99-113.

29. Mestre-Bach G, Granero R, Steward T, Fernandez-Aranda F, Bano M, Aymami N, et al. Reward and punishment sensitivity in women with gambling disorder or compulsive buying: implications in treatment outcome. Journal of Behavioral Addictions. 2016;5(4):658-65.

30. Matheson FI, Sztainert T, Lakman Y, Steele SJ, Ziegler CP, Ferentzy P. Prevention and treatment of problem gambling among older adults: a scoping review. Journal of Gambling Issues. 2018(39). Plain language summary available at https://www.greo.ca/Modules/EvidenceCentre/Details/a-review-of-prevention-and-treatment-of-problem-gamblingamong-older-adults

31. Ramos-Grille I, Goma-i-Freixanet M, Aragay N, Valero S, Valles V. Predicting treatment failure in pathological gambling: the role of personality traits. Addictive Behaviours. 2015;43:54-9.

32. Ronzitti S, Lutri V, Meleck S, Smith N, Bowden-Jones H. Smoking and gambling disorder: does tobacco use influence treatment outcome? Journal of Gambling Studies. 2015;31(3):1107-17.

33. Smith D, Harvey P, Humeniuk R, Battersby M, Pols R. Effects of affective and anxiety disorders on outcome in problem gamblers attending routine cognitive-behavioural treatment in South Australia. Journal of Gambling Studies. 2015;31(3):1069-83.

34. Linnet J, Jeppsen Mensink M, de Neergaard Bonde J, Winterdahl M. Treatment of gambling disorder patients with comorbid depression. Acta Neuropsychiatrica. 2017;29(6):356-62. Plain language summary available at https://www. greo.ca/Modules/EvidenceCentre/Details/a-comparison-of-treatment-effects-in-gamblers-with-and-without-depression

35. Soberay A, Faragher JM, Barbash M, Brookover A, Grimsley P. Pathological gambling, co-occurring disorders, clinical presentation, and treatment outcomes at a university-based counseling clinic. Journal of Gambling Studies. 2014;30(1):61-9.

36. Riley BJ. The role of homework in exposure-based CBT outcome for problem gambling. International Gambling Studies. 2015;15(3):394-407. Plain language summary available at https://www.greo.ca/Modules/EvidenceCentre/ Details/the-relationship-between-homework-engagement-and-cbt-treatment-outcome-for-proble

37. DiClemente CC, Corno CM, Graydon MM, Wiprovnick AE, Knoblach DJ. Motivational interviewing, enhancement, and brief interventions over the last decade: a review of reviews of efficacy and effectiveness. Psycholology of Addictive Behaviors. 2017;31(8):862-87.

38. Stea JN, Hodgins DC, Fung T. Abstinence versus moderation goals in brief motivational treatment for pathological gambling. Journal of Gambling Studies. 2015;31(3):1029-45.

39. Nehlin C, Nyberg F, Jess K. Brief intervention within primary care for at-risk gambling: a pilot study. Journal of Gambling Studies. 2016;32(4):1327-35. Plain language summary available at https://www.greo.ca/Modules/EvidenceCentre/Details/brief-intervention-risk-gambling-can-be-delivered-primary-health-care-settings 
40. Toneatto T. Single-session interventions for problem gambling may be as effective as longer treatments: results of a randomized control trial. Addictive Behaviors. 2016;52:58-65. Plain language summary available at https://www.greo.cal Modules/EvidenceCentre/Details/brief-treatment-one-session-effective-longer-treatments-problem-gambling

41. Yakovenko I, Quigley L, Hemmelgarn BR, Hodgins DC, Ronksley P. The efficacy of motivational interviewing for disordered gambling: systematic review and meta-analysis. Addictive Behaviors. 2015;43:72-82. Plain language summary available at https://www.greo.ca/Modules/EvidenceCentre/Details/motivational-interviewing-meta-analysisconfirms-its-value-treatment-option

42. Boudreault C, Giroux I, Jacques C, Goulet A, Simoneau H, Ladouceur R. Efficacy of a self-help treatment for at-risk and pathological gamblers. Journal of Gambling Studies. 2018;34(2):561-80. Plain language summary available at https://www.greo.ca/Modules/EvidenceCentre/Details/treating-problem-gambling-with-a-workbook-and-motivationalinterviews

43. Miller WR, Rollnick S. Motivational interviewing: preparing people to change addictive behavior. New York: Guilford Press; 1991.

44. Garcia-Caballero A, Torrens-Lluch M, Ramirez-Gendrau I, Garrido G, Valles V, Aragay N. The efficacy of Motivational Intervention and Cognitive-Behavioral Therapy for pathological gambling. Adicciones. 2018;30(3):219-24.

45. Pfund RA, Whelan JP, Peter SC, Meyers AW. Can a motivational letter increase attendance to psychological treatment for gambling disorder? Psychological Services. 2018. Plain language summary available at https://www.greo.ca/Modules/ EvidenceCentre/Details/a-motivational-letter-may-be-able-to-increase-attendance-at-psychological-treatme

46. Chebli JL, Blaszczynski A, Gainsbury SM. Internet-based interventions for addictive behaviours: a systematic review. Journal of Gambling Studies. 2016;32(4):1279-304. Plain language summary available at https://www.greo.ca/Modules/ EvidenceCentre/Details/a-systematic-review-of-internet-based-interventions-for-addictive-behaviours

47. van der Maas M, Shi J, Elton-Marshall T, Hodgins DC, Sanchez S, Lobo DS, et al. Internet-based interventions for problem gambling: scoping review. JMIR Mental Health. 2019;6(1):e65. Plain language summary available at https://www.greo.ca/Modules/EvidenceCentre/Details/how-is-the-internet-being-used-to-deliver-problem-gamblinginterventions

48. Rodda SNL, Dan I. ; Dowling, Nicki A. ; Hammond, David. Online and on-demand support for people affected by problem gambling: the potential for e-mental health interventions. 2016. Available from: https://www.greo.ca/Modules/ EvidenceCentre/Details/online-and-on-demand-support-for-people-affected-by-problem-gambling-the-potenti

49. Danielsson AK, Eriksson AK, Allebeck P. Technology-based support via telephone or web: a systematic review of the effects on smoking, alcohol use and gambling. Addictive Behaviors. 2014;39(12):1846-68.

50. Gainsbury S, Blaszczynski A. A systematic review of Internet-based therapy for the treatment of addictions. Clinical Psychology Review. 2011;31(3):490-8.

51. Hodgins DC, Cunningham JA, Murray R, Hagopian S. Online self-directed interventions for gambling disorder: randomized controlled trial. Journal of Gambling Studies. 2019;35(2):635-51. Plain language summary available at https://www.greo.ca/Modules/EvidenceCentre/Details/comparing-treatment-outcomes-of-two-online-self-directedgambling-interventions

52. Bucker L, Bierbrodt J, Hand I, Wittekind C, Moritz S. Effects of a depression-focused internet intervention in slot machine gamblers: a randomized controlled trial. PLoS One. 2018;13(6):e0198859. Plain language summary available at https://www.greo.ca/Modules/EvidenceCentre/Details/online-intervention-program-may-help-treat-problemgambling-in-people-with-depres 
53. Boughton RR, Jindani F, Turner NE. Group treatment for women gamblers using web, teleconference and workbook: effectiveness pilot. International Journal of Mental Health and Addiction. 2016;14(6):1074-95. Plain language summary available at https://www.greo.ca/Modules/EvidenceCentre/Details/web-based-group-counselling-can-help-women-dealwith-problem-gambling

54. Neighbors C, Rodriguez LM, Rinker DV, Gonzales RG, Agana M, Tackett JL, et al. Efficacy of personalized normative feedback as a brief intervention for college student gambling: a randomized controlled trial. Journal of Consulting Clinical Psychology. 2015;83(3):500-11.

55. Boughton R, Jindani F, Turner NE. Closing a treatment gap in Ontario: pilot of a tutorial workbook for women gamblers. Journal of Gambling Issues. 2017(36):199-231. Plain language summary available at https://www.greo.ca/Modules/ EvidenceCentre/Details/evaluating-a-tutorial-workbook-for-women-gamblers

56. Campos MD, Rosenthal RJ, Chen Q, Moghaddam J, Fong TW. A self-help manual for problem gamblers: the impact of minimal therapist guidance on outcome. International Journal of Mental Health and Addiction. 2015;14(4):579-96.

Plain language summary available at https://www.greo.ca/Modules/EvidenceCentre/Details/impact-self-help-manual-orwithout-therapist-guidance-gambling-outcomes

57. Kim HS, Hodgins DC, Bellringer M, Abbott M. Gender differences among helpline callers: prospective study of gambling and psychosocial outcomes. Journal of Gambling Studies. 2016;32(2):605-23. Plain language summary available at https://www.greo.ca/Modules/EvidenceCentre/Details/gambling-and-mental-health-outcomes-improvefor-helpline-callers-despite-gender-d

58. Valdivia-Salas S, Blanchard KS, Lombas AS, Wulfert E. Treatment-seeking precipitators in problem gambling: analysis of data from a gambling helpline. Psychology of Addictive Behaviors. 2014;28(1):300-6.

59. Ranta J, Bellringer M, Garrett N, Abbott M. Can a brief telephone intervention for problem gambling help to reduce co-existing depression? A three-year prospective study in New Zealand. Journal of Gambling Studies. 2019;35(2):617-33. Plain language summary available at https://www.greo.ca/Modules/EvidenceCentre/Details/can-a-brief-telephoneintervention-for-problem-gambling-help-to-reduce-depression

60. Khayyat-Abuaita U, Ostojic D, Wiedemann A, Arfken CL, Ledgerwood DM. Barriers to and reasons for treatment initiation among gambling help-line callers. Journal of Nervous and Mental Disease. 2015;203(8):641-5. Plain language summary available at https://www.greo.ca/Modules/EvidenceCentre/Details/perceived-absence-gambling-problemsand-treatment-unavailability-are-most-significant

61. Weinstock J, Burton S, Rash CJ, Moran S, Biller W, Krudelbach N, et al. Predictors of engaging in problem gambling treatment: data from the West Virginia Problem Gamblers Help Network. Psychology of Addictive Behaviors.

$2011 ; 25(2): 372-9$.

62. Nayoski N, Hodgins DC. The efficacy of individual community reinforcement and family training (CRAFT) for concerned significant others of problem gamblers. Journal of Gambling Issues. 2016;2016(33):189-212. Plain language summary available at https://www.greo.ca/Modules/EvidenceCentre/Details/individual-community-reinforcement-and-family-training-craft-could-support-fami

63. Jimenez-Murcia S, Tremblay J, Stinchfield R, Granero R, Fernandez-Aranda F, Mestre-Bach G, et al. The involvement of a concerned significant other in gambling disorder treatment outcome. Journal of Gambling Studies. 2017;33(3):937-53. Plain language summary available at https://www.greo.ca/Modules/EvidenceCentre/Details/including-spouses-or-partners-in-therapy-sessions-helps-patients-recover-from-gam 
64. Nilsson A, Magnusson K, Carlbring P, Andersson G, Gumpert CH. The development of an internet-based treatment for problem gamblers and concerned significant others: a pilot randomized controlled trial. Journal of Gambling Studies. 2017. Plain language summary available at https://www.greo.ca/Modules/EvidenceCentre/Details/internetbased-behavioural-couples-therapy-shows-promise-as-a-treatment-for-probl

65. Lee BK, Awosoga O. Congruence couple therapy for pathological gambling: a pilot randomized controlled trial. Journal of Gambling Studies. 2015;31(3):1047-68.

66. Tremblay J, Dufour M, Bertrand K, Blanchette-Martin N, Ferland F, Savard AC, et al. The experience of couples in the process of treatment of pathological gambling: couple vs. individual therapy. Frontiers in Psychology. 2017;8:2344. Plain language summary available at https://www.greo.ca/Modules/EvidenceCentre/Details/the-experiences-ofgamblers-and-their-partners-in-couple-versus-individual-therap

67. Morefield K, Walker C, Smith D, Harvey P, Dunn K, Battersby M. An inpatient treatment program for people with gambling problems: synopsis and early outcomes. International Journal of Mental Health and Addiction. 2014;12(3):367-79.

68. Gori A, Craparo G, Caretti V, Giannini M, Iraci-Sareri G, Bruschi A, et al. Impulsivity, alexithymia and dissociation among pathological gamblers in different therapeutic settings: a multisample comparison study. Psychiatry Research. 2016;246:789-95.

69. Leavens E, Marotta J, Weinstock J. Disordered gambling in residential substance use treatment centers: an unmet need. Journal of Addictive Diseases. 2014;33(2):163-73.

70. Buchner UG, Erbas B, Sturmer M, Arnold M, Wodarz N, Wolstein J. Inpatient treatment for pathological gamblers in Germany: setting, utilization, and structure. Journal of Gambling Studies. 2015;31(1):257-79.

71. Muller KW, Wolfling K, Dickenhorst U, Beutel ME, Medenwaldt J, Koch A. Recovery, relapse, or else? Treatment outcomes in gambling disorder from a multicenter follow-up study. European Psychiatry. 2017;43:28-34. Plain language summary available at https://www.greo.ca/Modules/EvidenceCentre/Details/treatment-outcomes-and-changes-inpersonality-after-gambling-disorder-treatment

72. Roberts A, Murphy R, Turner J, Sharman S. Predictors of dropout in disordered gamblers in UK residential treatment. Journal of Gambling Studies. 2019. Plain language summary available at https://www.greo.ca/Modules/EvidenceCentre/ Details/predictors-of-dropout-in-disordered-gamblers-in-uk-residential-treatment

73. Kovanen L, Basnet S, Castren S, Pankakoski M, Saarikoski ST, Partonen T, et al. A randomised, double-blind, placebocontrolled trial of as-needed naltrexone in the treatment of pathological gambling. European Addiction Research. 2016;22(2):70-9. Plain language summary available at https://www.greo.ca/Modules/EvidenceCentre/Details/clinicaltrial-naltrexone-treatment-pathological-gambling-finland

74. Chamberlain SR, Grant JE. Efficacy of pharmacological interventions in targeting decision-making impairments across substance and behavioral addictions. Neuropsychology Review. 2019;29(1):93-102. Plain language summary available at https://www.greo.ca/Modules/EvidenceCentre/Details/decision-making-problems-are-common-in-people-addictedto-alcohol-and-gambling

75. Grant JE, Odlaug BL, Black DW, Fong T, Davtian M, Chipkin R, et al. A single-blind study of 'as-needed' ecopipam for gambling disorder. Annals of Clinical Psychiatry. 2014;26(3):179-86.

76. Goslar M, Leibetseder M, Muench HM, Hofmann SG, Laireiter AR. Pharmacological treatments for disordered gambling: a meta-analysis. Journal of Gambling Studies. 2019;35(2):415-45. Plain language summary available at https://www.greo.ca/Modules/EvidenceCentre/Details/a-review-of-drug-treatments-to-address-gambling-disorder 
77. Ward S, Smith N, Bowden-Jones H. The use of naltrexone in pathological and problem gambling: a UK case series. Journal of Behavioral Addictions. 2018;7(3):827-33. Plain language summary available at https://www.greo.ca/Modules/ EvidenceCentre/Details/naltrexone-as-a-treatment-for-pathological-and-problem-gambling

78. Deepmala, Slattery J, Kumar N, Delhey L, Berk M, Dean O, et al. Clinical trials of N-acetylcysteine in psychiatry and neurology: a systematic review. Neuroscience and Biobehavioral Reviews. 2015;55:294-321.

79. de Brito AM, de Almeida Pinto MG, Bronstein G, Carneiro E, Faertes D, Fukugawa V, et al. Topiramate combined with cognitive restructuring for the treatment of gambling disorder: a two-center, randomized, double-blind clinical trial. Journal of Gambling Studies. 2017;33(1):249-63. Plain language summary available at https://www.greo.ca/Modules/ EvidenceCentre/Details/topiramate-combined-with-cognitive-behavioural-therapy-can-be-effective-in-treati

80. Naish KR, Vedelago L, MacKillop J, Amlung M. Effects of neuromodulation on cognitive performance in individuals exhibiting addictive behaviors: a systematic review. Drug and Alcohol Dependence. 2018;192:338-51.

81. Zack M, Cho SS, Parlee J, Jacobs M, Li C, Boileau I, et al. Effects of high frequency repeated transcranial magnetic stimulation and continuous theta burst stimulation on gambling reinforcement, delay discounting, and Stroop interference in men with pathological gambling. Brain Stimulation. 2016;9(6):867-75. Plain language summary available at https:// www.greo.ca/Modules/EvidenceCentre/Details/stimulating-brain-cells-with-magnetic-fields-may-reduce-a-pathologicalgamblers

82. Gay A, Boutet C, Sigaud T, Kamgoue A, Sevos J, Brunelin J, et al. A single session of repetitive transcranial magnetic stimulation of the prefrontal cortex reduces cue-induced craving in patients with gambling disorder. European Psychiatry. 2017;41:68-74. Plain language summary available at https://www.greo.ca/Modules/EvidenceCentre/Details/stimulatingthe-prefrontal-cortex-can-help-patients-with-gambling-disorder-reduce

83. Sauvaget A, Bulteau S, Guilleux A, Leboucher J, Pichot A, Valriviere P, et al. Both active and sham low-frequency rTMS single sessions over the right DLPFC decrease cue-induced cravings among pathological gamblers seeking treatment: a randomized, double-blind, sham-controlled crossover trial. Journal of Behavioral Addictions. 2018:1-11.

84. Spagnolo PA, Gomez Perez LJ, Terraneo A, Gallimberti L, Bonci A. Neural correlates of cue- and stress-induced craving in gambling disorders: implications for Transcranial Magnetic Stimulation interventions. European Journal of Neuroscience. 2018. Plain language summary available at https://www.greo.ca/Modules/EvidenceCentre/Details/thepotential-use-of-repetitive-transcranial-magnetic-stimulation-to-target-cravi

85. Rogers J. Gamblers Anonymous in the United Kingdom: a qualitative analysis. Alcoholism Treatment Quarterly. 2019;37(1):123. Plain language summary available at https://www.greo.ca/Modules/EvidenceCentre/Details/exploringhow-gamblers-anonymous-meetings-are-run-in-the-united-kingdom

86. Schuler A, Ferentzy P, Turner NE, Skinner W, Mclsaac KE, Ziegler CP, et al. Gamblers Anonymous as a recovery pathway: a scoping review. Journal of Gambling Studies. 2016;32(4):1261-78. Plain language summary available at https://www.greo.ca/Modules/EvidenceCentre/Details/review-gamblers-anonymous-treating-problem-gambling

87. Linardatou C, Parios A, Varvogli L, Chrousos G, Darviri C. An 8-week stress management program in pathological gamblers: a pilot randomized controlled trial. Journal of Psychiatric Research. 2014;56:137-43.

88. Challet-Bouju G, Bruneau M, Victorri-Vigneau C, Grall-Bronnec M. Cognitive remediation interventions for gambling disorder: a systematic review. Frontiers in Psychology. 2017;8:1961. Plain language summary available at https://www. greo.ca/Modules/EvidenceCentre/Details/cognitive-remediation-as-a-new-approach-for-managing-gambling-disorder

89. Wittekind CE, Bierbrodt J, Ludecke D, Feist A, Hand I, Moritz S. Cognitive bias modification in problem and pathological gambling using a web-based approach-avoidance task: a pilot trial. Psychiatry Research. 2019;272:171-81. 
90. Rossini-Dib D, Fuentes D, Tavares H. A naturalistic study of recovering gamblers: what gets better and when they get better. Psychiatry Research. 2015;227(1):17-26. Plain language summary available at https://www.greo.ca/Modules/ EvidenceCentre/Details/which-treatment-outcomes-best-predict-gambling-recovery

91. Mooney A, Roberts A, Bayston A, Bowden-Jones H. The piloting of a brief relational psychodynamic protocol (psychodynamic addiction model) for problem gambling and other compulsive addictions: a retrospective analysis. Counselling and Psychotherapy Research. 2019. Plain language summary available at https://www.greo.ca/Modules/ EvidenceCentre/Details/a-psychodynamic-treatment-protocol-for-difficult-to-treat-people-with-problem-gam

92. Matheson FI, Parsons J, Dastoori P, Juando-Prats C, Fryszberg I, Hamilton-Wright S. Women creating community: supporting women to manage problem gambling through arts-based programming. Guelph, ON; 2019. Available from: https://www.greo.ca/Modules/EvidenceCentre/Details/women-creating-community-supporting-women-to-manageproblem-gambling-through-art

93. Matheson Fl, Hamilton-Wright S, Kryszajtys DT, Wiese JL, Cadel L, Ziegler C, et al. The use of self-management strategies for problem gambling: a scoping review. BMC Public Health. 2019;19(1):445. Plain language summary available at https://www.greo.ca/Modules/EvidenceCentre/Details/exploring-self-management-strategies-that-couldbe-used-to-deal-with-problem-gamb

94. Maniaci G, La Cascia C, Picone F, Lipari A, Cannizzaro C, La Barbera D. Predictors of early dropout in treatment for gambling disorder: The role of personality disorders and clinical syndromes. Psychiatry Research. 2017;257:540-5. Plain language summary available at https://www.greo.ca/Modules/EvidenceCentre/Details/certain-psychiatric-disorders-arerelated-to-early-dropout-from-gambling-treatmen

95. Pfund RA, Peter SC, Whelan JP, Meyers AW. When does premature treatment termination occur? Examining session-by-session dropout among clients with gambling disorder. Journal of Gambling Studies. 2017. Plain language summary available at https://www.greo.ca/Modules/EvidenceCentre/Details/examining-when-clients-with-gamblingproblems-are-likely-to-drop-out-of-treatment

96. Monnat SM, Bernhard B, Abarbanel BL, St John S, Kalina A. Exploring the relationship between treatment satisfaction, perceived improvements in functioning and well-being and gambling harm reduction among clients of pathological gambling treatment programs. Community Mental Health Journal. 2014;50(6):688-96.

97. Gomes K, Pascual-Leone A. A resource model of change: client factors that influence problem gambling treatment outcomes. Journal of Gambling Studies. 2015;31(4):1651-69. Plain language summary available at https://www.greo.ca/ Modules/EvidenceCentre/Details/client-factors-help-or-hinder-problem-gambling-treatment

98. Skinner WJW, Littman-Sharp N, Leslie J, Ferentzy P, Zaheer S, Smit Quosai T, et al. Best practices for the treatment of older adult problem gamblers. Journal of Gambling Issues. 2018(39). Plain language summary available at https://www. greo.ca/Modules/EvidenceCentre/Details/best-practices-for-the-treatment-of-gambling-problems-among-older-adults

99. Merkouris SS, Thomas SA, Browning CJ, Dowling NA. Predictors of outcomes of psychological treatments for disordered gambling: a systematic review. Clinical Psychology Review. 2016:48:7-31. Plain language summary available at https://www.greo.ca/Modules/EvidenceCentre/Details/review-individual-and-treatment-characteristics-affecttreatment-outcomes-disordered

100. David D, Cristea I, Hofmann SG. Why cognitive behavioral terapy is the current gold standard of psychotherapy. Frontiers in Psychiatry. 2018;9:4.

101. Foundations Recovery Network. Recovery: Abstinence vs. Moderation [Web page]. 2020 [Available from: https:// dualdiagnosis.org/drug-addiction/recovery-abstinence-vs-moderation/] 
102. World Health Organization. Addiction Severity Index - Lite Version (ASI-Lite) [Web page]. n.d. [Available from: https://www.who.int/substance abuse/research tools/addictionseverity/en/]

103. Petry NM. Validity of a gambling scale for the Addiction Severity Index. The Journal of Nervous and Mental Disease. 2003;191(6):399-407.

104. Bunglawala Z. Please, don't call me BAME or BME! [Web page]. GOV.UK2019 [Available from: https://civilservice. blog.gov.uk/2019/07/08/please-dont-call-me-bame-or-bme/]

105. Rockloff MJ, Schofield G. Factor analysis of barriers to treatment for problem gambling. Journal of Gambling Studies. 2004;20(2):121-6.

106. Sutton Uplift. Behavioural Couples Therapy (BCT) [Web page]. 2015 [Available from: https://www.suttonuplift.co.uk/ psychological-therapies/what-do-we-offer/behavioural-couples-therapy-bct]

107. Recovery Research Institute. Behavioral Couples Therapy (BCT) [Web page]. n.d. [Available from: https://www. recoveryanswers.org/resource/behavioral-couples-therapy/]

108. GambleAware. Brief intervention guide: addressing risk and harm related to gambling. 2017. Available from: https://about.gambleaware.org/media/1817/gambleaware-brief-intervention-guide.pdf

109. Gambling Research Exchange Ontario. CPGl [Web Page]. 2019 [Available from: https://www.greo.ca/en/topics/ cpgi.aspx]

110. Psychology Today. Cognitive Behavioral Therapy [Web page]. n.d. [Available from: https://www.psychologytoday. $\mathrm{com} / \mathrm{gb} /$ therapy-types/cognitive-behavioral-therapy]

111. Fan $\mathrm{Q}$, Liao L, Pan G. The application of cognitive remediation therapy in the treatment of mental disorders. Shanghai Archives of Psychiatry. 2017;29(6):373-5.

112. Clark DA. Cognitive restructuring. The Wiley handbook of cognitive behavioral therapy. 2013:1-22.

113. Meyers RJ, Miller WR, Hill DE, Tonigan JS. Community reinforcement and family training (CRAFT): engaging unmotivated drug users in treatment. Journal of Substance Abuse. 1998;10(3):291-308.

114. National Institute on Drug Abuse. Comorbidity: substance use disorders and other mental illnesses [Web page]. 2018 [Available from: https://www.drugabuse.gov/publications/drugfacts/comorbidity-substance-use-disordersother-mental-illnesses]

115. Lee BK, Rovers M, MacLean L. Training counsellors in congruence couple therapy: a controlled evaluation study. Prepared for the Ontario Problem Gambling Research Centre; 2006.

116. Lee BK. Congruence couple therapy for pathological gambling. International Journal of Mental Health and Addiction. 2009;7(1):45-67.

117. Psychology Today. Conscientiousness [Web page]. 2020 [Available from: https://www.psychologytoday.com/ gb/basics/conscientiousness]

118. Park C-B, Park SM, Gwak AR, Sohn BK, Lee J-Y, Jung HY, et al. The effect of repeated exposure to virtual gambling cues on the urge to gamble. Addictive Behaviors. 2015;41:61-4.

119. Potenza M. How central is dopamine to pathological gambling or gambling disorder? Frontiers in Behavioral Neuroscience. 2013;7(206). 
120. American Psychiatric Association. Diagnostic statistical manual of mental disorders: DSM-5TM. Arlington. VA American Psychiatric Publishing. 2013.

121. Bell CC. DSM-IV: Diagnostic and Statistical Manual of Mental Disorders. Journal of the American Medical Association. 1994;272(10):828-9.

122. American Psychiatric Association. Diagnostic criteria from DSM-IV-TR: American Psychiatric Pub; 2000.

123. Rolston A, Lloyd-Richardson E. What is emotion regulation and how do we do it. Cornell Research Program on Self-Injury and Recovery Available at: http://wwwselfinjurybctrcornelledu/perch/resources/what-is-emotion-regulationsinfo-briefpdf. 2017.

124. Oakes J, Riley B. Exposure therapy: a treatment for problem gambling. 2009.

125. Psychology Today. Extroversion [Web page]. 2020 [Available from: https://www.psychologytoday.com/gb/basics/ extroversion]

126. Gamblers Anonymous England Wales and Ulster. Gamblers Anonymous [Web page]. 2019 [Available from: https://www.gamblersanonymous.org.uk/]

127. Kassinove JI. Development of the gambling attitude scales: preliminary findings. Journal of Clinical Psychology. 1998;54(6):763-71.

128. Young MM, Wohl MJA. The gambling craving scale: psychometric validation and behavioral outcomes. Psychology of Addictive Behaviors. 2009;23(3):512-22.

129. Steenbergh TA, Meyers AW, May RK, Whelan JP. Development and validation of the Gamblers' Beliefs Questionnaire. Psychology of Addictive Behaviors. 2002;16(2):143-9.

130. Neighbors C, Lostutter TW, Larimer ME, Takushi RY. Measuring gambling outcomes among college students. Journal of Gambling Studies. 2002;18(4):339-60.

131. Casey LM, Oei TPS, Melville KM, Bourke E, Newcombe PA. Measuring self-efficacy in gambling: the Gambling Refusal Self-Efficacy Questionnaire. Journal of Gambling Studies. 2008;24(2):229-46.

132. Raylu N, Oei TPS. The Gambling Related Cognitions Scale (GRCS): development, confirmatory factor validation and psychometric properties. Addiction. 2004;99(6):757-69.

133. Kim SW, Grant JE, Potenza MN, Blanco C, Hollander E. The Gambling Symptom Assessment Scale (G-SAS): a reliability and validity study. Psychiatry Research. 2009;166(1):76-84.

134. Smith DP, Pols RG, Battersby MW, Harvey PW. The Gambling Urge Scale: reliability and validity in a clinical population. Addiction Research \& Theory. 2013;21(2):113-22.

135. Pettorruso M, De Risio L, Martinotti G, Di Nicola M, Ruggeri F, Conte G, et al. Targeting the glutamatergic system to treat pathological gambling: current evidence and future perspectives. BioMed Research International. 2014;2014.

136. Tremblay J, Savard A-C, Blanchette-Martin N, Dufour M, Bertrand K, Ferland F, et al. Integrative Couple Treatment for Pathological Gambling/ICT-PG: description of the therapeutic process. Canadian Journal of Addiction. 2015;6(2):54-61.

137. Richards D, Enrique A, Palacios J, Duffy D. Internet-Delivered Cognitive Behaviour Therapy. In: Cognitive Behavioral 
Therapy and Clinical Applications: IntechOpen; 2017.

138. Minati L, Campanhã C, Critchley HD, Boggio PS. Effects of transcranial direct-current stimulation (tDCS) of the dorsolateral prefrontal cortex (DLPFC) during a mixed-gambling risky decision-making task. Cognitive Neuroscience. 2012;3(2):80-8.

139. Shaffer HJ, LaBrie R, Scanlan KM, Cummings TN. Pathological gambling among adolescents: Massachusetts gambling screen (MAGS). Journal of Gambling Studies. 1994;10(4):339-62.

140. Psychology Today. Mindfulness [Web page]. 2020 [Available from: https://www.psychologytoday.com/ca/basics/ mindfulness]

141. Drug Rehab Southampton. Motivational Enhancement Therapy Overview [Web page]. 2018 [Available from: https://drugrehab-southampton.co.uk/treatment/motivational-enhancement-therapy/]

142. Royal College of Nursing. How motivational interviewing works [Web page]. 2020 [Available from: https://www.rcn. org.uk/clinical-topics/supporting-behaviour-change/motivational-interviewing]

143. Wickwire Jr EM, Burke RS, Brown SA, Parker JD, May RK. Psychometric evaluation of the National Opinion Research Center DSM-IV Screen for Gambling Problems (NODS). The American Journal on Addictions. 2008;17(5):392-5.

144. Psychology Today. Neuroticism [Web page]. 2020 [Available from: https://www.psychologytoday.com/gb/basics/ neuroticism]

145. ChEBI. CHEBI:60605 - opioid receptor antagonist [Web page]. 2015 [Available from: https://www.ebi.ac.uk/chebi/ searchld. do? chebild $=60605]$

146. Ladouceur R, Dumont J, Giroux I, Jacques C, Sylvain C, Boutin C, et al. Entrevue Diagnostique sur le Jeu Pathologique, Révisée. Québec: Centre Québécois d'Excellence pour la Prévention et le Traitement du Jeu. 2000.

147. Moreira MT, Oskrochi R, Foxcroft DR. Personalised normative feedback for preventing alcohol misuse in university students: Solomon three-group randomised controlled trial. PloS one. 2012;7(9):e44120-e.

148. Psychology Today. Placebo: Sugar Pills [Web page]. 2020 [Available from: https://www.psychologytoday.com/ca/ basics/placebo]

149. Ferris J, Wynne H. The Canadian Problem Gambling Index: final report. Canadian Consortium for Gambling Research; 2001. Available from: http://www.ccgr.ca/en/projects/resources/CPGl-Final-Report-English.pdf

150. Psychology Today. Psychodynamic Therapy [Web page]. 2020 [Available from: https://www.psychologytoday.com/ gb/therapy-types/psychodynamic-therapy

151. O'Neill K. Psychoeducation for problem gambling. In: Evidence-based treatments for problem gambling: Springer; 2017. p. 9-17.

152. NHS. Psychotherapy [Web page]. 2020 [Available from: https://www.nhsinform.scot/tests-and-treatments/counselling-and-therapies/psychotherapy]

153. NHS. Health news glossary: Behind the headlines [Web page]. 2020 [Available from: https://www.nhs.uk/news/ health-news-glossary/\#randomised-controlled-trial-rct]

154. GoodTherapy. Residential Treatment [Web page]. 2019 [Available from: https://www.goodtherapy.org/

learn-about-therapy/modes/residential-treatment] 
155. NHS. Overview: selective serotonin reuptake inhibitors (SSRIs) [Web page]. 2020 [Available from: https://www.nhs. uk/conditions/ssri-antidepressants/]

156. Zuckerman M. Sensation seeking. In: Handbook of individual differences in social behavior. New York, NY, US: The Guilford Press; 2009. p. 455-65.

157. Lesieur HR, Blume SB. The South Oaks Gambling Screen (SOGS): a new instrument for the identification of pathological gamblers. American Journal of Psychiatry. 1987;144(9).

158. Grant JE, Steinberg MA, Kim SW, Rounsaville BJ, Potenza MN. Preliminary validity and reliability testing of a structured clinical interview for pathological gambling. Psychiatry Research. 2004;128(1):79-88.

159. Vékony $T$, Németh VL, Holczer A, Kocsis $K$, Kincses ZT, Vécsei L, et al. Continuous theta-burst stimulation over the dorsolateral prefrontal cortex inhibits improvement on a working memory task. Scientific Reports. 2018;8(1):14835.

160. Sobell L, Sobell M, Buchan G, Cleland P, Fedoroff I, Leo G, et al. Timeline Followback Method (Drugs, Cigarettes, and Marijuana). 1996.

161. Thair H, Holloway AL, Newport R, Smith AD. Transcranial Direct Current Stimulation (tDCS): a beginner's guide for design and implementation. Frontiers in Neuroscience. 2017;11:641.

162. NHS. NICE approves migraine magnet therapy [Web page]. 2014 [Available from: https://www.nhs.uk/news/neurology/nice-approves-migraine-magnet-therapy/]

163. BACP. Types of therapy: an A-Z of therapeutic approaches [Web page]. 2020 [Available from: https://www.bacp.co.uk/ about-therapy/types-of-therapy/]

164. McMillen J, Wenzel M. Measuring problem gambling: assessment of three prevalence screens. International Gambling Studies. 2006;6(2):147-74.

165. Harvard University. The World Health Organization World Mental Health Composite International Diagnostic Interview (WHO WMH-CIDI) [Web page]. 2017 [Available from: https://www.hcp.med.harvard.edu/wmhcidi/about-thewho-wmh-cidi/]

166. Pallanti S, DeCaria C, Grant J, Urpe M, Hollander E. Reliability and validity of the Pathological Gambling adaptation of the Yale-Brown Obsessive-Compulsive Scale (PG-YBOCS). Journal of Gambling Studies. 2005;21:431-43. 